\title{
LA PERSISTENCIA DE UN MODO DE PRODUCCIÓN DOMÉSTICO durante el período Tardío: el caso de Corral Alto (Antofagasta de la Sierra, Argentina)
}

\author{
Jennifer Grant ${ }^{1}$ y Patricia Escola ${ }^{2}$
}

\section{* Introducción}

Resumen

En este trabajo presentamos un análisis detallado de las arqueofaunas recuperadas en el sitio Corral Alto (Quebrada de Miriguaca) a fin de abordar los patrones de explotación de recursos faunísticos implementados por las comunidades agropastoriles que ocuparon la microrregión de Antofagasta de la Sierra (Provincia de Catamarca, Puna Meridional Argentina) durante el período Tardío (ca. 1000-500 AP). Los resultados obtenidos hasta el momento permiten señalar, para el sector del curso medio del río Miriguaca, la persistencia de prácticas de explotación de recursos animales indicativas de estrategias económicas diversificadas llevadas a cabo a pequeña escala. Dichas estrategias habrían funcionado en simultáneo junto con aquellas observadas en otros sectores del área de estudio, caracterizadas por el desarrollo de una producción agropastoril especializada y a gran escala.

Palabras claves: período Tardío - camélidos - pastoreo - caza - Puna.

In this article, a detailed analysis on the archaeofaunal remains uncovered at the Corral Alto site (Quebrada de Miriguaca) are presented with the aim of teasing out animal resource exploitation patterns implemented by the agropastoralist communities that inhabited the Antofagasta de la Sierra micro-region during the Late Period (ca. 1000-500 BP).

The results obtained to date highlight that along the middle sector of the Miriguaca River there was a persistence in the exploitation of animal resources indicative of a small-scale diversified economic strategies. Said strategies would have been employed alongside those observed in other sectors of the study area, characterized in the development of a specialized agropastoralist production on a large-scale.

Key words: Late Period - camelids - pastoralism - hunting - Puna.

Recibido: Enero 2015. Aceptado: Octubre 2015
La cantidad de estudios realizados sobre arqueofaunas recuperadas en distintos sitios del noroeste argentino y asignados al período Tardío o de Desarrollos Regionales (ca. 1000 años AP) ha crecido notablemente en el transcurso de esta última década (López Campeny et al. 2005; Urquiza y Aschero 2006; Yacobaccio y Catá 2006; Mengoni Goñalons 2007; Pratolongo 2008; Izeta et al. 2009; Mercolli 2010; Ortiz y Urquiza 2012; Belotti López de Medina 2013; Urquiza et al. 2013; Grant 2014). Dicha tendencia estaría indicando, a nuestro parecer, el reconocimiento de la importancia del análisis de los conjuntos óseos como una vía clave para discutir diferentes aspectos de la vida de los pueblos prehispánicos, tales como patrones de subsistencia, asentamiento, uso del espacio, aspectos rituales, jerarquías sociales, etc. A su vez, esto se complementa con la diversificación temática alcanzada por los estudios arqueofaunísticos lo cual, junto con la introducción de nuevas metodologías - tales como osteometría y análisis de isotopos estables-, ha llevado a replantear modelos de uso corriente como así también a enriquecer discusiones sobre el manejo y la explotación de recursos animales por distintos grupos sociales en variados ámbitos geográficos. En este sentido, por ejemplo, las aproximaciones metodológicas que buscan discriminar entre las especies silvestres ( $V_{i}$ cugna vicugna y Lama guanicoe) y domésticas (Lama glama y Vicugna pacos) de camélidos presentes en los distintos

1 Instituto Nacional de Antropología y Pensamiento Latinoamericano (INAPL). 3 de Febrero 1378 (C1426BJN), Buenos Aires, ARGENTINA. Email: jennygrantlett@gmail.com

2 Consejo Nacional de Investigaciones Científicas y Técnicas (CONICET) - Escuela de Arqueología (UNCa). Maximio Victoria S/N Predio Universitario (CP 4700), San Fernando del Valle de Catamarca, ARGENTINA. Email: suyu@arnet.com.ar 
conjuntos faunísticos, han conducido a nuevos planteamientos respecto a los cambios en la importancia de las actividades de caza y de pastoreo a través del tiempo y del espacio. Asimismo, el análisis de variaciones de tamaño en restos óseos asignados a camélidos domésticos, como así también la combinación de tales resultados junto con perfiles de mortalidad y análisis de isotopos estables, han permitido profundizar en el estudio de los patrones de explotación de rebaños de animales e identificar estrategias de explotación mixta u especializada de los mismos para obtener diversos productos tales como fibra, carne o su empleo como animal de carga (Mengoni Goñalons 2008; Dantas 2012; Gasco 2013; Grant 2014).

Lo anteriormente apuntado conduce a destacar que el campo de la zooarqueología no se limita solamente al estudio de hábitos dietarios pasados. En este sentido, el estudio de restos animales permite alcanzar un entendimiento más profundo de las complejas interacciones entre humanos y animales, así como también una mayor comprensión de las sociedades pasadas (Rusell 2012).

Con la finalidad de sumar esfuerzos en esta dirección, en el presente trabajo llevamos a cabo un análisis minucioso del conjunto arqueofaunístico recuperado en la excavación de dos estructuras (E1 y E2) así como también de tres sondeos estratigráficos realizados en el sitio Corral Alto. Este último se encuentra ubicado en el curso medio del río Miriguaca, en el denominado Sector Intermedio (sensu Olivera 1992) de la micro-región de Antofagasta de la Sierra (provincia de Catamarca, puna meridional argentina), con dataciones radiocarbónicas que permiten asignarlo cronológicamente a momentos del período Tardío en el desarrollo sociocultural de la región (ca. 1000 a $500 \mathrm{AP}$ ).

El objetivo del mencionado análisis es el de proveer un conocimiento detallado de la tafonomía y la utilización económica de los principales recursos faunísticos explotados por los antiguos pobladores del mencionado sitio. Específicamente, centraremos nuestra atención en los resultados obtenidos del estudio de los restos de camélidos, puesto que son los que predominan en el conjunto analizado, con el fin de ofrecer interpretaciones en cuanto a la obtención, manejo, procesamiento y consumo de estos animales por los habitantes prehispánicos del sitio.
Asimismo, los resultados alcanzados serán confrontados con la información disponible respecto a la evidencia faunística procedente de sitios "Formativos" y "Tardíos" de otros sectores microambientales del área de estudio, con el propósito de comprender el rol particular jugado por el sitio Corral Alto dentro de la economía prehispánica de Antofagasta de la Sierra.

De esta manera, nuestra intención en esta oportunidad es aportar datos e interpretaciones que puedan ser utilizados en la construcción de la historia ocupacional del sitio y con ello contribuir a alcanzar un mejor entendimiento de la dinámica de los grupos agropastoriles tardíos que habitaron esta porción del paisaje de la puna meridional argentina.

\section{Antofagasta de la Sierra y las sociedades del Tardío}

El área de investigación, la micro-región de Antofagasta de la Sierra, se ubica en el ángulo noroeste de la provincia de Catamarca, entre los $25^{\circ} 50^{\prime}$ y $26^{\circ} 10^{\prime}$ S y entre los $67^{\circ} 30^{\prime}$ y $67^{\circ} 10^{\prime} \mathrm{O}$. Sus límites son: hacia el oeste, la línea de frontera argentino-chilena; al norte y al este, la provincia de Salta; al sur, la cordillera de San Buenaventura, y al sureste la sierra de Laguna Blanca. Una serie de cordones montañosos surca el área - sierras de Antofalla, de Calalaste, de Toconquis y de Laguna Blanca- que, junto con las características particulares de los distintos sectores microambientales (sensu Olivera 1992), otorgan gran diversidad a la zona. La red hidrográfica es endorreica alimentada por escasas precipitaciones, el régimen de deshielo (de noviembre a marzo) y las aguas subterráneas. Los principales ríos son el Calalaste, el Toconquis, el Punilla/Antofagasta y sus afluentes, dentro de los cuales se destacan los ríos Las Pitas, Curuto, Los Colorados y Miriguaca. Este último, donde se concentra nuestro estudio, comprende una quebrada estrecha y protegida, con un curso de agua permanente cuya cuenca de drenaje posee una superficie de $131 \mathrm{~km} 2$, presentando una excelente vega de buena pastura (Figura 1).

Para este sector de la puna meridional argentina se advierte, en términos generales, una extrema aridez (clima árido andino puneño) con precipitaciones de régimen estival inferiores a 100-150 mm anuales, aunque ausentes en algunas temporadas. Por su parte, la temperatura media anual es de $9,5^{\circ} \mathrm{C}$, con gran amplitud térmica 


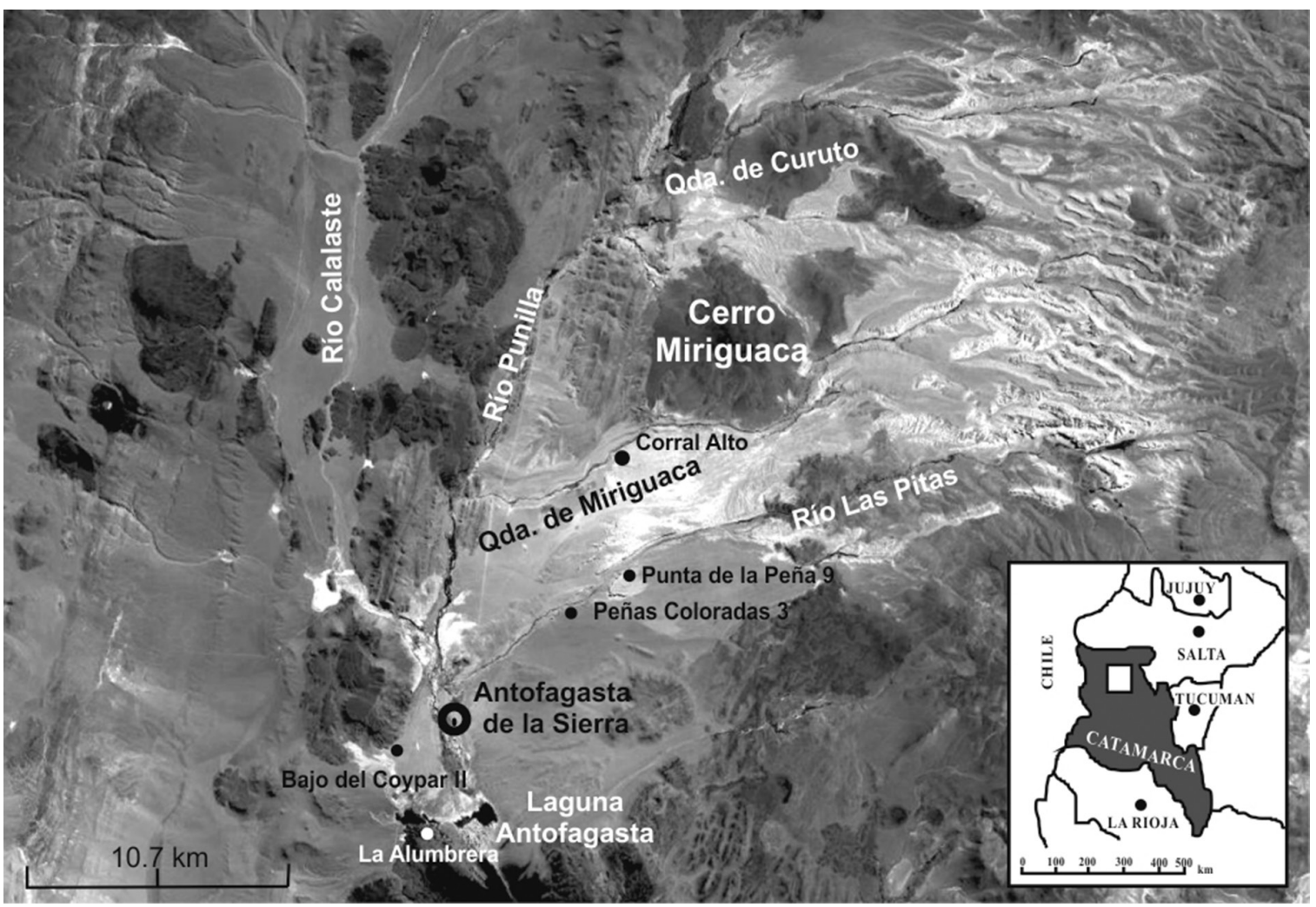

Figura 1. Área de Antofagasta de la Sierra (Catamarca, noroeste Argentino), con la ubicación de la quebrada del río Miriguaca y los sitios mencionados en el texto.

diurna/nocturna y estacional, y baja presión atmosférica. Se presentan heladas durante todo el año, especialmente intensas entre mayo y agosto.

Dado que se trata de un ambiente puneño, la micro-región se caracteriza por presentar un paisaje con alta heterogeneidad. Al respecto, aun dentro de un radio de pocos kilómetros, se pueden observar importantes variaciones, condicionadas fundamentalmente por la ubicación altitudinal y las características topográficas. De este modo, es posible distinguir en la cuenca de Antofagasta de la Sierra tres sectores microambientales con alta concentración de recursos (Olivera 1992):

1) El Fondo de Cuenca, que comprende el tramo final del curso inferior del río Punilla y su desembocadura en la laguna de Antofagasta, con una altitud de 3400-3550 msnm. 2) Los sectores intermedios, que corresponden a los cursos inferior y medio de los ríos Las Pitas y Miriguaca, con una altitud de 3400-3800 msnm (modificado por Escola et al. 2013).
3) Las Quebradas de Altura, que corresponden a los cursos medio y superior de los ríos Las Pitas y Miriguaca, con una altitud de $3800-4600 \mathrm{msnm}$.

Cabe resaltar que, en los sectores intermedios, las áreas de fondo de quebrada con desarrollo de vega constituyen las de mejor productividad. Asimismo, una oferta forrajera apreciable y una provisión continua de agua aparecen acompañadas por la presencia de terrenos aptos para cultivos de escasa extensión tipo melgas (Olivera 1992).

Las investigaciones llevadas a cabo en Antofagasta de la Sierra para el período Tardío han señalado que, a partir de ca. 1000 años AP, durante una fase árida de retracción de vegas y disminución de los volúmenes hídricos (Tchilinguirian 2008), habrían comenzado a darse grandes cambios en la economía y en el patrón de asentamiento, lo que ha sido asociado a un proceso de creciente complejización sociopolítica en la región. Dicho proceso se habría caracterizado por el cambio desde un sistema 
basado en la familia nuclear y la familia extensa hacia el surgimiento de jefaturas o sociedades corporativas que habrían sustraído fuerza de trabajo y bienes del trabajo inter e intrafamiliar (Olivera y Viglinani 2000, 2002; Martel y Aschero 2007; Martel 2009; Salminci 2012; Elías 2014).

Los modos de vida anteriores comenzarían a cambiar, principalmente en el fondo de cuenca, estructurándose un nuevo paisaje social (Cohen 2011; Salminci 2012). De este modo, se observa un crecimiento de la población, la aparición de centros habitacionales semiurbanos con un interesante grado de planificación y se agudiza la tendencia iniciada alrededor de los 1800 años AP hacia el incremento de la producción agrícola, utilizándose terrenos más provechosos para el cultivo intensivo y extensivo (Olivera y de Aguirre 1995; Olivera y Vigliani 2000, 2002; Salminci 2012; Tchilingurian y Olivera 2012). Asimismo, para estos momentos comenzarían a aparecer evidencias de un manejo más complejo de los rebaños de llamas con el desarrollo de variedades especializadas orientadas a la producción de fibra y transporte (Olivera 1997, 2001; Grant 2008; Olivera y Grant 2008; Reigadas 2008).

Por último, la creciente complejidad sociopolítica observada ha sido relacionada con un incremento de la práctica caravanera (Olivera y Vigliani 2000, 2002; Olivera 2001; Podestá y Olivera 2006; Olivera y Grant 2008), cuya existencia como mecanismo de interacción habría estado presente desde, por lo menos, el Formativo Tardío (Olivera 2001; Martel y Aschero 2007). Dicho incremento estaría atestiguado por numerosas evidencias, tales como representaciones rupestres que muestran la aparición en distintos sectores de motivos que aluden a caravanas, evidencias de intercambio a distancia de elementos exóticos (Martel y Aschero 2007), recuperación de tarabitas (Raviña et al. 2007; Olivera et al. 2008), puestos asociados a actividades de caravanero (Cohen 2011; Urquiza et al. 2013), entre otros.

Ahora, si bien la creciente complejidad sociopolítica y el nuevo paisaje social serían evidentes fundamentalmente en el fondo de cuenca con la presencia del poblado de La Alumbrera y los extensos campos de cultivo de Bajo del Coypar (Olivera y Vigliani 2000, 2002; Salminci 2012), en los sectores intermedios de la micro-región este proceso no se advertiría tan claramente. Por un lado, registros vinculados a representaciones rupestres localizadas en dichos sectores estarían señalando la existencia de una situación de conflicto o tensión entre los grupos emplazados en el fondo de cuenca del Punilla y las antiguas unidades familiares de pastores que habitaban los sectores intermedios (Aschero 2000; Martel y Aschero 2007). Por otro lado, estudios recientes en el sitio Peñas Coloradas 3 cumbre (Cohen 2011, 2014), en la quebrada de Las Pitas, estarían reforzando la existencia de esta situación de tensión mostrando la persistencia de los modos de vida de estas familias de pastores. En este sentido, se plantea la posibilidad de que estas familias, lejos de jugar un rol pasivo en el marco de una posible centralización del poder político en el fondo de cuenca, pudieran haber conservado en las quebradas subsidiarias del Punilla cierta autonomía local.

\section{El sitio Corral Alto}

Este sitio se encuentra localizado en el curso medio del río Miriguaca, a $3680 \mathrm{msnm}$, presentando características particulares en cuanto a su emplazamiento puesto que se ubica sobre una terraza sobreelevada, lo que permite un amplio control visual de la quebrada del río (Escola et al. 2013).

En el sitio es posible diferenciar dos grandes sectores o espacios arquitectónicos discontinuos, compuestos por un número escaso de recintos y diferenciados por una marcada pendiente entre ellos (Figura 2). El primer sector hacia el suroeste ("Patio") presenta un muro de pirca seca, de baja altura, que delimita un espacio semicircular de grandes dimensiones (una superficie de $360 \mathrm{mz}$ ) contra el farallón ignimbrítico. En su interior pueden diferenciarse cuatro estructuras circulares de pirca seca, tres se ubican contra la pared del farallón y la restante opuesta a ellos, adosada a la estructura de pircado de grandes dimensiones aludida inicialmente. Próximos a los muros de los recintos, cabe destacar la presencia de un conjunto de orificios circulares alineados, interpretados preliminarmente como horadaciones ejecutadas con la finalidad de sustentar vigas, que habrían estado vinculadas con el sostén de estructuras de techado (Escola et al. 2013). Continuando en dirección noreste, un extenso muro de pirca seca $(c a .20 \mathrm{~m}$ ) guía la circulación en el sitio, obligando a transitar por un estrecho 
pasillo de pronunciada pendiente, que queda limitado por el muro y la pared del farallón ("Sector noroeste y Pasillo"). Dicho pasillo conduce hacia el segundo sector (noreste), que se encuentra ubicado en la parte más baja del sitio (superficie del sector $48,7 \mathrm{~m} 2$ ). Allí se registró un conjunto de estructuras rectangulares de pirca seca y muros elevados, dispuestas aprovechando un bloque de derrumbe de importantes dimensiones. Aquí también se registraron orificios circulares alineados sobre la pared de ignimbrita, en la proximidad de las estructuras, mostrando un patrón arquitectónico recurrente en el sitio, que interpretamos en relación al reparo de ciertos espacios de uso y actividad.

En este último sector fueron excavadas dos estructuras (E1 y E2) de planta rectangular. La estructura E1 fue excavada prácticamente en su totalidad, al cubrir una superficie de $12 \mathrm{~m} 2$, y dejar un testigo de $3 \mathrm{~m} 2$. Se registraron dos niveles arqueológicos con una potencia de aproximadamente $15-20 \mathrm{~cm}$, correspondiendo la mayor parte de los hallazgos al nivel dos. Asimismo, se obtuvieron dos fechados radiocarbónicos. El primero de ellos, realizado por técnica de AMS sobre un endocarpo de chañar, y asociado a un contexto de ceniza con abundantes desechos de talla, restos óseos de fauna con evidencias de termoalteración, semillas y una punta de proyectil, correspondió a una fecha de $720 \pm 40$ años AP (Ua-33241). El segundo fechado, realizado sobre carbón, dio una datación de 660 \pm 60 años AP (LP 1986). Por otra parte, en la estructura E2 se excavaron sólo dos cuadrículas (2 m2) que involucraron, al igual que en la E1, dos niveles arqueológicos y una potencia aproximada de $15-20 \mathrm{~cm}$. Por último, se realizaron sondeos estratigráficos diagnósticos hacia el suroeste del sector denominado preliminarmente "Patio". Los mismos consistieron en tres cuadrículas de $1 \mathrm{~m} \mathrm{x} 1$ $\mathrm{m}$, donde se excavaron sólo dos niveles con muy escasa potencia $(5-6 \mathrm{~cm})$ y reducida cantidad de hallazgos.

Cabe destacar que los trabajos que se vienen desarrollando en este sitio parten de la hipótesis de que se trataría de una base residencial, cuyos ocupantes serían integrantes de unidades familiares de pastores, similares a las de

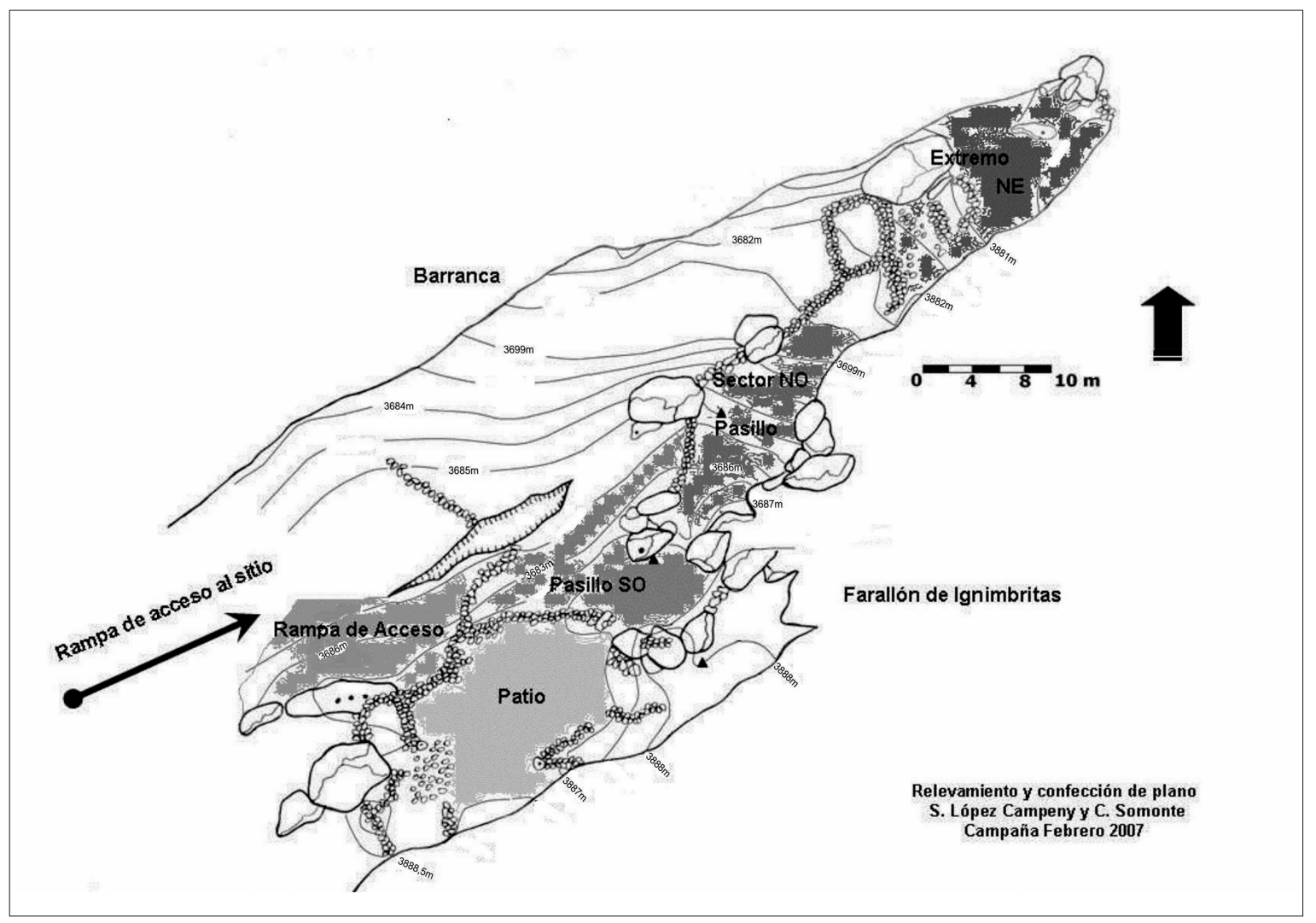

Figura 2. Plano del sitio Corral Alto. Ubicación de las estructuras y sectores analizados: E1, estructura 1; E2, estructura 2 y patio. 
otros sitios de los sectores intermedios. En este sentido, se destacan en Corral Alto interesantes similitudes con el entorno de Peñas Coloradas 3 cumbre: el emplazamiento particular del sitio, el control visual de la cuenca del río Miriguaca, la importancia de representaciones rupestres localizadas entre Corral Alto y el sitio Los Antiguos (Martel y Escola 2011), y la abundancia de recursos en la forma de agua y pasturas. Todo ello abre importantes perspectivas de investigación futura en este sitio, orientadas a discutir distintos aspectos de la organización sociopolítica de las sociedades del Tardío.

\section{* Metodología}

El material arqueofaunístico estudiado procede, en su mayoría, de las Estructuras 1 (E1) y 2 (E2), al que se le agregan algunos especímenes obtenidos en los sondeos realizados en el sector denominado "Patio" $(\mathrm{Pa})$.

Para la identificación de los especímenes óseos se utilizaron diversos atlas osteológicos de animales domésticos (p.e. Pacheco Torres et al. 1986; Barone 1987; Galotta y Galotta 1988) y la colección osteológica de referencia del Instituto Nacional de Antropología y Pensamiento Latinoamericano (Argentina). Se consideraron identificables todos los huesos o fragmentos que, como mínimo, pudieran asignarse a alguna región anatómica, y a nivel taxonómico, aquellos especímenes que se caracterizaron al nivel de orden o clase de un tamaño estipulado (Mengoni Goñalons 1999). En el caso de los restos asignados a Camelidae se buscó establecer, mediante análisis osteométricos, qué especies podían estar representadas dentro del conjunto. La implementación de este método sobre restos óseos de camélidos se basa en la existencia de un gradiente de tamaño, que en los Andes Centrales y centro-sur va desde la llama de mayor tamaño, pasando por el guanaco y finalmente la vicuña de menor tamaño (Elkin et al. 1991; Mengoni Goñalons y Yacobaccio 2006). La alpaca, por su parte, es una especie de camélido domesticado que no habita en la actualidad en el área de estudio y cuya presencia no ha sido detectada fehacientemente en épocas prehispánicas (Olivera y Elkin 1994; Grant 2010). Esto obedecería a características ambientales que no presentan el desarrollo de "bofedales" (extensas vegas de altura, muy húmedas, en general por encima de los $4000 \mathrm{msnm}$ ) que se consideran el hábitat ideal para la alpaca (Flores Ochoa 1982; Olive- ra 1997; Yacobaccio et al. 1997-1998).

Cada elemento analizado fue medido siguiendo los criterios definidos por Wing (1972), von den Driesch (1976) y Kent (1982) y resumidos en una lista elaborada por Elkin (1996) y Mengoni Goñalons (2007, com. pers.). En el caso de las falanges primeras, las mismas fueron discriminadas en delanteras y traseras siguiendo los criterios establecidos por Kent (1982). Sobre las mediciones que constituyen la muestra se aplicaron dos métodos: a) técnica de distancia de logaritmos o Logarithmic Size Index (LSI) de Meadow $(1987,1999)$ a través de la cual se comparó, mediante distancias logarítmicas, una sola medida osteométrica de cada espécimen arqueológico con la misma medida, correspondiente a un guanaco recuperado en la provincia de Salta, noroeste argentino (Mengoni Goñalons 2007, com. pers.), y b) análisis multivariados exploratorios siguiendo los criterios aplicados anteriormente por Menegaz et al. (1988), Izeta (2007) y Grant (2010). En este caso, se obtuvo para cada elemento medido una matriz de similitud con el coeficiente de distancia Manhattan o City-Block y se implementaron sobre las matrices resultantes análisis de conglomerados (UPGMA). Dichos análisis fueron realizados utilizando el software STATISTICA 6.0 de StatSoft Inc. Es necesario destacar que los análisis osteométricos se basan en muy pocos individuos comparativos, en especial de guanacos andinos, lo cual nos lleva a estimar que puede existir algún grado de error que no nos permita interpretar adecuadamente los resultados. En este trabajo se incorporan, para la aplicación de análisis multivariados, datos métricos de 12 ejemplares actuales de Lama glama y 17 de Vicugna vicugna de la micro-región de Antofagasta de la Sierra. En cuanto a los guanacos andinos, puesto que no habitan actualmente en el área de estudio, empleamos los datos métricos de dos ejemplares: uno procedente de las Cumbres Calchaquíes (Salta, código Lg. 350) (Mengoni Goñalons 2007, com. pers.) y un ejemplar adulto de sexo indeterminado de Tesoro de Arriba (Falda occidental del Aconquija, código Lg. 149) (Izeta 2007).

Respecto a la cuantificación, se ha empleado el número de especímenes óseos identificados por taxón (NISP) y el número mínimo de individuos (MNI) (Mengoni Goñalons 1999). Esta última medida se determinó teniendo en cuenta los criterios de lateralidad y el estado de fusión de los especímenes analizados (Lyman 1994; Mengoni 
Goñalons 1999). Además, sobre el NISP se registraron las diferentes variables referidas a procesos y agentes naturales (meteorización, marcas de roedores y carnívoros, improntas de raíces) y culturales (huellas culturales, termoalteración) que intervinieron en la integridad de los depósitos arqueológicos bajo estudio. El valor del Número Mínimo de Elementos (MNE) se obtuvo por los métodos de suma de fracciones (Klein y Cruz-Uribe 1984) y de zonas diagnósticas (Mengoni Goñalons 1999), tomando para cado caso el valor más alto obtenido. A partir de estos datos, se trabajó con las unidades anatómicas mínimas y sus proporciones (MAU y MAU\%) (Binford 1984; Mengoni Goñalons 1999).

La determinación de la edad de muerte de los taxones identificados se realizó con base al tamaño de los especímenes, las características del tejido óseo y el estado de fusión de los huesos (Davis 1989; Mengoni Goñalons 1999; Reitz y Wing 2008). Por otra parte, para la estimación de las clases de edad con base al estado de fusión epifisiaria se utilizaron, en elementos asignados a camélidos, las secuencias de fusión disponibles para alpaca (Kent 1982), guanaco norpatagónico (Kaufmann 2009) y camélidos en general (Wheeler 1999). Sin embargo, puesto que existen discrepancias entre tales secuencias, a la hora de construir los perfiles de supervivencia/mortalidad se ha utilizado la secuencia de fusión de huesos presentada por Wheeler (1999), junto con las seis categorías o grupos etarios allí empleadas, complementada con elementos adicionales incluidos en la base de datos de Kent (1982). De esta manera, en el caso de los camélidos se utilizaron las siguientes clases de edad: nonatos (o meses), neonatos o crías (hasta los 12 meses), juveniles (12-24 meses), subadultos (24-33 meses), adultos jóvenes (33-36 meses) y adultos (36 o más).

Finalmente, con objeto de realizar interpretaciones sobre aspectos de la economía de los antiguos habitantes del sitio, se realizaron estudios de correlación entre indicadores de abundancia (\%MAU) y la densidad ósea e índice de utilidad de alimento (FUI) (Stahl 1999; Mengoni Goñalons 2001).

\section{* Resultados alcanzados en los análisis}

La muestra total está conformada por 4146 especímenes óseos, de los cuales 1862 (NISP) fueron identificados anatómica y taxonómicamente. En la Tabla 1 se resumen los resultados de su identificación, con 524 especímenes caracterizados a nivel de orden o inferior, y otros 1338 asignados a alguna clase de tamaño corporal estipulado (Brain 1981; Mengoni Goñalons 1999). Estos últimos resultaron ser fragmentos óseos y dentarios de mamífero grande (peso corporal $>50 \mathrm{~kg}$ ) que representan zonas esqueletarias generales (principalmente porciones de cráneo, vértebras indeterminadas, superficies articulares no diferenciadas y diáfisis no diagnósticas de huesos largos). El resto del conjunto $(n=2284)$ no pudo ser identificado a ningún nivel taxonómico debido al tamaño pequeño de los fragmentos y a la falta de rasgos diagnósticos en los mismos que permitiera asignarlos a alguna categoría taxonómica (NID). Se trata, en general, de pequeños fragmentos de tejido cortical u esponjoso. En relación a esto último cabe destacar que, dentro de los especímenes no identificados, un $74 \%$ corresponde a fragmentos menores a $2 \mathrm{~cm}$ y un $99 \%$ a fragmentos menores a $5 \mathrm{~cm}$, dando cuenta del alto grado de fragmentación de la muestra.

Como se observa en la Tabla 1, la mayoría de los restos óseos identificados a nivel de orden o inferior pertenecen a Camelidae y Artiodactyla. Los especímenes correspondientes a Rodentia no superan el 1,2\% dentro de la muestra (porcentaje basado en el NISP). Si tomamos por separado las estructuras excavadas hasta el momento, observamos que este patrón se repite. De esta manera, para el caso de la E1, de 434 especímenes identificados a nivel de orden o inferior, 401 corresponden a Camelidae, 28 a Artiodacyla y tan solo cinco a Rodentia. Teniendo en cuenta la menor extensión de las excavaciones del conjunto recuperado en E2, de 80 especímenes, 73 fueron identificados como pertenecientes a Camelidae, seis a Artiodactyla y solo uno a Rodentia, mientras que de los sondeos realizados en el patio, 10 especímenes corresponden a Camelidae. Cabe destacar que esta composición taxonómica es de frecuente registro en muchos sitios agropastoriles del noroeste argentino, en particular de la Puna Sur (Olivera 1997; López 2003).

Respecto a los factores de índole tafonómica que operaron sobre el conjunto faunístico, la Tabla 2 presenta los resultados del análisis de los efectos de la meteorización sobre los especímenes identificados a nivel de orden o inferior. De los 244 especímenes que permitieron el análisis de dicho proceso (el resto del conjunto presenta signos de termoalteración, ver infra), un 36\% ( $n=88)$ se 


\begin{tabular}{|l|c|c|c|c|}
\hline \multicolumn{1}{|c|}{ Taxa } & Estructura 1 & Estructura 2 & Patio & Total NSP \\
\hline $\begin{array}{l}\text { Mamífero } \\
\text { grande }\end{array}$ & 1128 & 138 & 72 & 1338 \\
\hline Artiodactyla & 28 & 6 & - & 34 \\
\hline Camelidae & 393 & 69 & 9 & 471 \\
\hline Lamaglama & 4 & - & - & 4 \\
\hline $\begin{array}{l}\text { Vicugna } \\
\text { vicugna }\end{array}$ & 4 & 4 & 1 & 9 \\
\hline Rodentia & 4 & 1 & - & 5 \\
\hline Chinchilidae & 1 & - & - & 1 \\
\hline $\begin{array}{l}\text { Subtotal } \\
\text { identificados } \\
\text { (NISP) }\end{array}$ & 1562 & 218 & 82 & 1862 \\
\hline $\begin{array}{l}\text { Subtotal no } \\
\text { identificados } \\
\text { (NID) }\end{array}$ & 1854 & 244 & 186 & 2284 \\
\hline Total & 3416 & 462 & 268 & 4146 \\
\hline
\end{tabular}

Tabla 1. Número de especímenes identificados (NISP) y no identificados (NID) por estructura analizada.

encuentra meteorizado en estadios mayores a 2 (siguiendo la escala desarrollada por Behrensmeyer 1978), lo cual puede considerarse alto, e implicaría una exposición a la meteorización subaérea relativamente prolongada. Este patrón se repite en las dos estructuras excavadas, con un $35 \%$ de los especímenes de la E1 $(n=192)$ y un $39 \%$ de la $E_{2}(n=51)$ en estadios 3, 4 y, en menor medida, 5 de meteorización.

En cuanto a las alteraciones por otro tipo de agentes, como carnívoros o roedores, no presentan valores importantes. Se han detectado marcas de roedor en tan solo tres especímenes óseos recuperados en la Estructura 1, lo que indica que este agente no parece haber incidido en forma importante en la configuración de las muestras. Por otro lado, no hemos encontrado marcas resultado del accionar de carnívoros y sólo se han registrado modificaciones óseas resultantes de la acción de raíces en 18 especímenes, 16 observadas en las arqueofaunas de
E1 y tan solo dos sobre especímenes recuperados en E2, indicando asimismo la poca incidencia de estos agentes naturales en general.

En lo que sigue presentaremos un análisis más detallado del subconjunto formado por los restos de Camelidae, por ser los que predominan en el sitio en general, con especial hincapié en los conjuntos recuperados en E1 y E2, ya que para "Patio" se recuperaron muy pocos especímenes (NISP 10).

\section{Análisis del subconjunto de camélidos}

Comenzaremos esta sección presentando los resultados obtenidos de la identificación específica de camélidos mediante la aplicación de las dos técnicas osteométricas mencionadas previamente. De esta manera, en la Figura 3 fueron volcados los resultados logarítmicos de la comparación de los distintos elementos arqueológicos. En la misma, la medida estándar de guanaco a partir de la cual se comparó cada elemento está representada gráficamente como la línea o. Los valores más alejados hacia la izquierda son más pequeños que el estándar, y fueron asignados a vicuñas, mientras que los más alejados hacia la derecha son más grandes, correspondiendo a llamas (Elkin 1996). Sin embargo, existen valores que oscilan entre $\pm 0,01$ y $\pm 0,02$, los cuales son bastante aproximados al estándar de guanaco, aunque también podrían superponerse con los de las llamas de menor tamaño. Debido a ello, en estos casos seguimos a López (2003) y asignamos a estos especímenes a la categoría de "llama-guanaco". Los elementos y las medidas utilizados para identificar las especies presentes en el conjunto corresponden al ancho máximo de la superficie articular proximal de seis falanges proximales ( $1 F A 2)$ y cinco falanges mediales (2FA2) y el ancho máximo del extremo distal de un metapodio (MCP6).

\begin{tabular}{|c|c|c|c|c|c|c|c|c|c|c|c|c|c|c|}
\hline Estadios & \multicolumn{2}{|c|}{ o } & \multicolumn{2}{|c|}{1} & \multicolumn{2}{|c|}{2} & \multicolumn{2}{|c|}{3} & \multicolumn{2}{|c|}{4} & \multicolumn{2}{|c|}{5} & \multicolumn{2}{|c|}{ Total } \\
\hline Estructuras & $\mathrm{N}$ & $\%$ & $\mathrm{~N}$ & $\%$ & $\mathrm{~N}$ & $\%$ & $\mathrm{~N}$ & $\%$ & $\mathrm{~N}$ & $\%$ & $\mathrm{~N}$ & $\%$ & $\mathrm{~N}$ & $\%$ \\
\hline Estructura 1 & 25 & 13 & 35 & 18,2 & 64 & 33,3 & 37 & 19,3 & 22 & 11,5 & 9 & 4,7 & 192 & 100 \\
\hline Estructura 2 & 4 & 7,9 & 7 & 13,7 & 20 & 39,2 & 8 & 15,7 & 3 & 5,9 & 9 & 17,6 & 51 & 100 \\
\hline Patio & - & - & - & - & 1 & 100 & - & - & - & - & - & - & 1 & 100 \\
\hline Total & 29 & 12 & 42 & 17,2 & 85 & 34,8 & 45 & 18,4 & 25 & 10,2 & 18 & 7,4 & 244 & 100 \\
\hline
\end{tabular}

Tabla 2. Frecuencia de etapas de meteorización en especímenes de artiodáctilos y camélidos por estructura. 


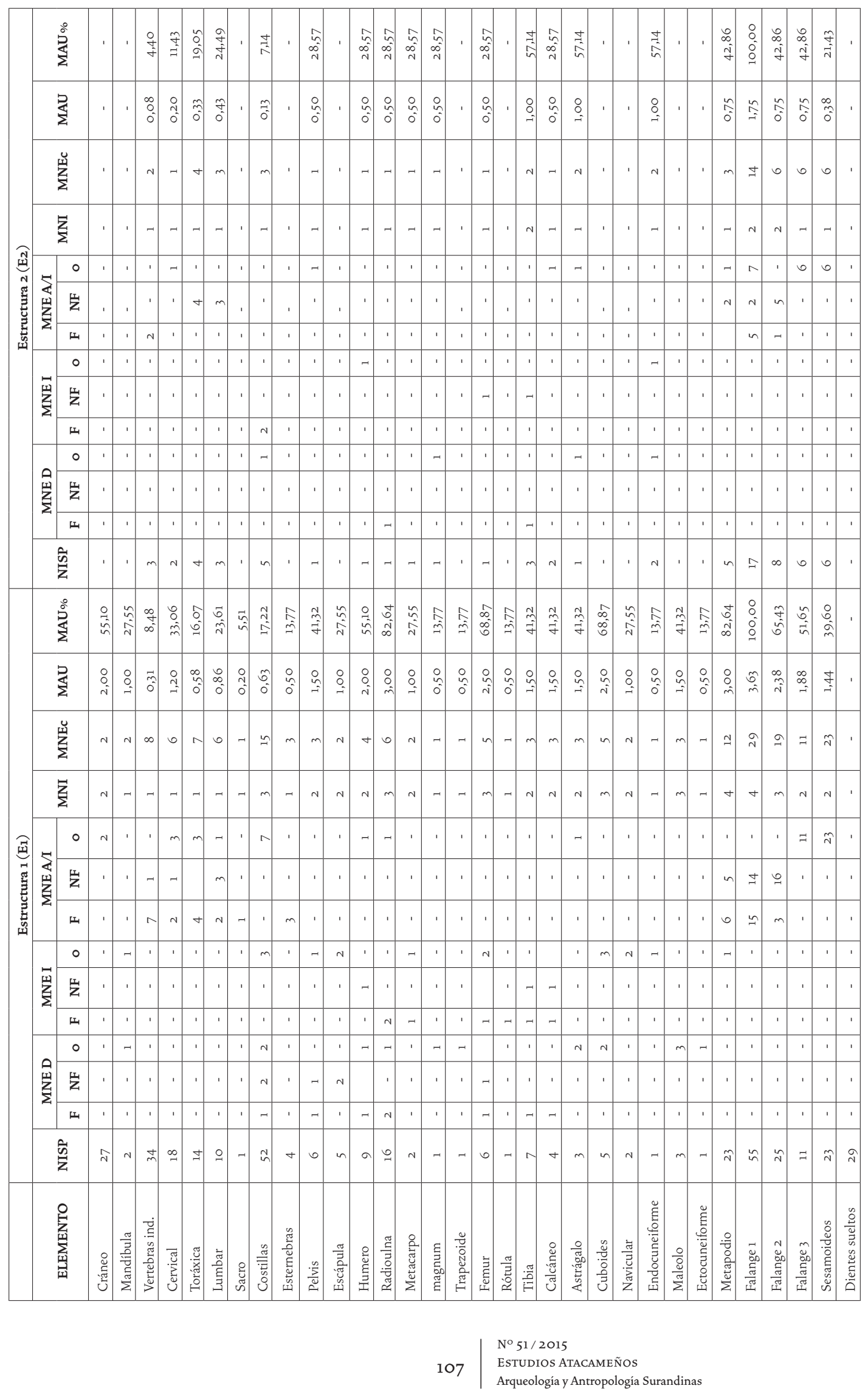




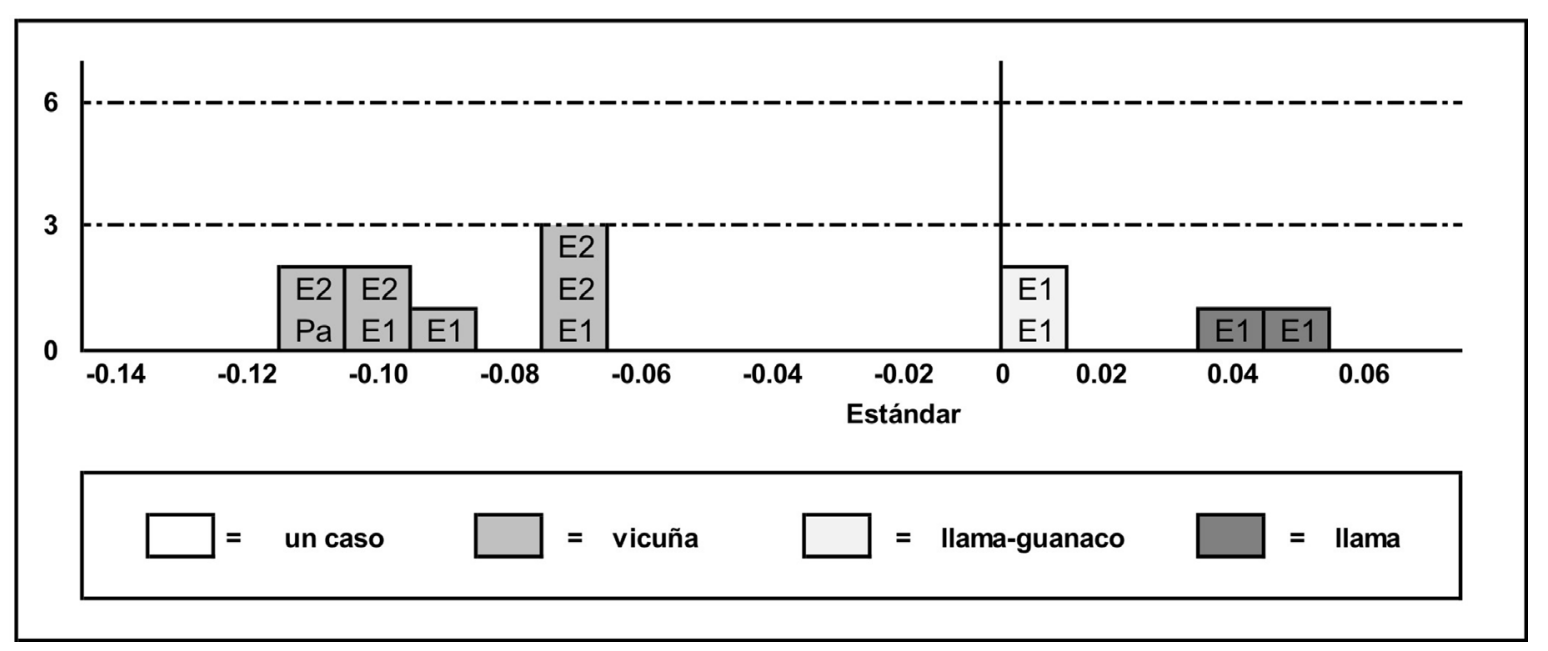

Figura 3. Histograma representando la diferencia logarítmica entre medidas de guanaco norandino moderno y especímenes arqueológicos del sitio Corral Alto.

Si bien sólo se pudieron medir unos pocos especímenes ( $\mathrm{n}=12$ ), ya que para aplicar este método los huesos deben estar fusionados, tener los puntos de medición necesarios y poseer un buen estado de conservación (von den Driesch 1976; Elkin 1996), se pudo observar una tendencia que apunta a una proporción relativamente alta de especímenes correspondientes a animales silvestres, dado que ocho de los 12 ejemplares analizados fueron asignados a vicuñas. Por su parte, dos especímenes mostraron valores altos, asignados por lo tanto a llamas, mientras que se observó un tercer grupo formado por dos ejemplares de falanges segundas cuyos valores se distribuyen alrededor del estándar de guanaco andino, asignándolos mediante este método a la categoría de llama-guanaco.

La aplicación de análisis multivariados, al incluir un mayor número de caracteres por elemento y de individuos de referencia, permitió ajustar a una resolución de grano más fino estos últimos resultados. De esta manera, en el gráfico de análisis de agrupamientos (Figura 4-A), se observa que los ejemplares de falanges segundas, tanto los asignados previamente a llamas como los correspondientes a la categoría llama-guanaco, se agrupan junto a las llamas actuales de la región de Antofagasta de la Sierra. La presencia de llamas en el sitio también ha sido registrada mediante el análisis exploratorio de dos variables de un fragmento distal de falange primera (Figura 4-B). En cuanto a los metapodios y a las falanges primeras, podemos ver en las Figuras 4.C, D, E y F que todos los elementos arqueológicos se agrupan junto con ejemplares correspondientes a vicuñas actuales de la región de estudio, coincidiendo con los resultados obtenidos mediante el empleo de la técnica de logaritmos. Por su parte, el análisis de la distribución en el espacio de las distintas especies de camélidos reveló la presencia de vicuña en los tres sectores estudiados, mientras que los ejemplares asignados a llama fueron recuperados hasta el momento únicamente en El.

Perfil anatómico. En la Tabla 3 y en la Figura 5 se presenta la frecuencia de partes esqueletarias de los conjuntos recuperados en E1 y E2, calculadas según distintas unidades. Una primera cualidad que se destaca del subconjunto Camelidae de Eı es la alta diversidad de partes esqueletarias recuperadas, con casi todos los huesos de la carcasa representados, tanto del esqueleto axial como del apendicular. Los elementos correspondientes a este último predominan por sobre el primero, mostrando a la falange proximal como la parte esqueletaria más representada en términos del MAU\%, seguida por el metapodio, la radioulna y el fémur. En el caso del esqueleto axial, se destaca la alta representación de fragmentos correspondientes a cráneo, seguido por pelvis y vértebras cervicales (Figura 5).

En E2, si bien la muestra recuperada es más pequeña que la del conjunto anterior, notamos nuevamente la presencia de una alta diversidad de partes esqueletarias tanto axiales como apendiculares, siendo estas últimas las que 

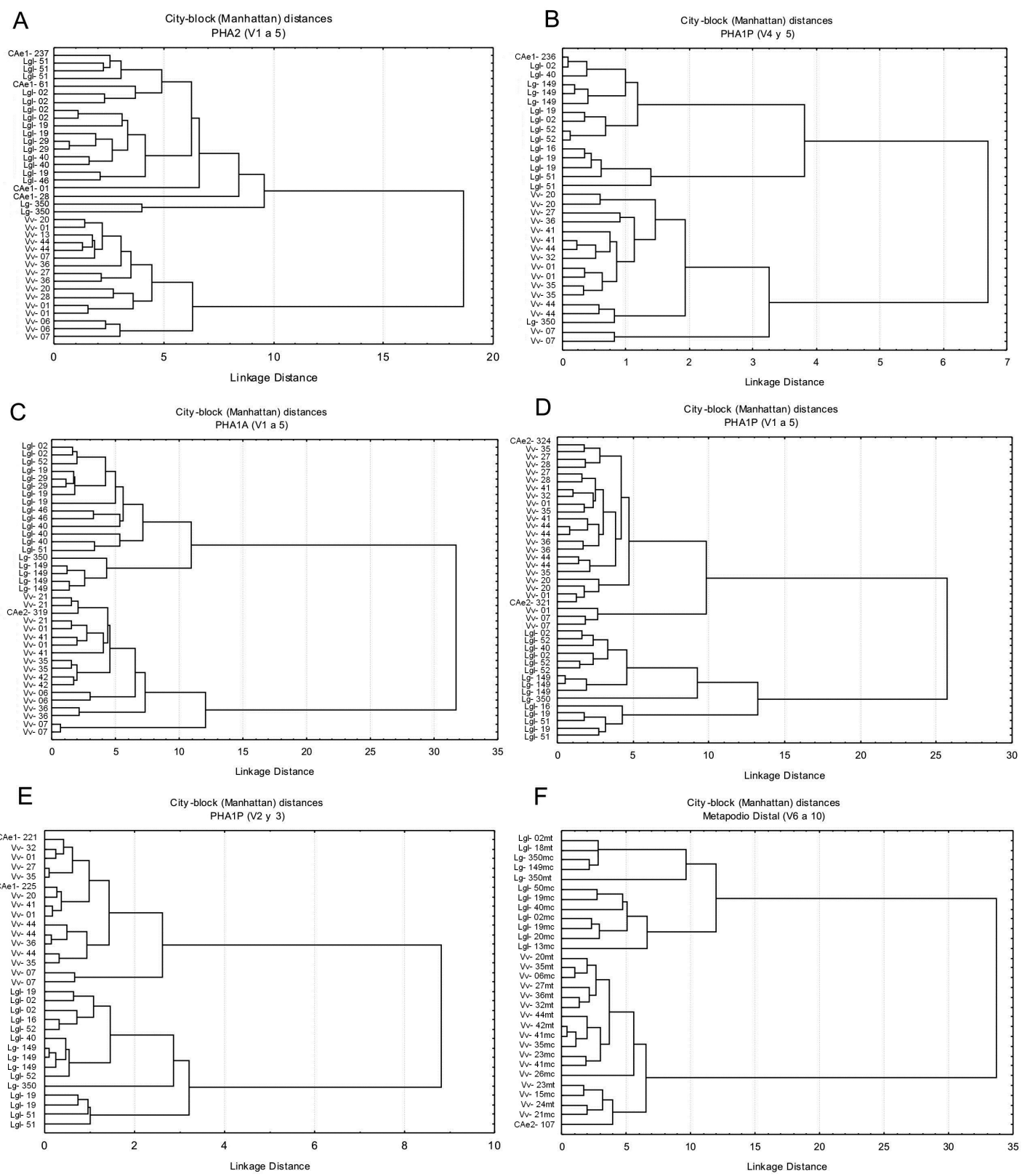

Figura 4. Resultado del Análisis de Conglomerados. A) Falange 2; B), C), D) y E) Falange Proximal; F) Metapodio distal. Referencias: $\mathrm{Lg}$ = Lama guanicoe de referencia, $\mathrm{Lgl}=$ Lama glama de referencia, Vv= Vicugna vicugna de referencia, el resto corresponde a elementos arqueológicos de Corral Alto. 


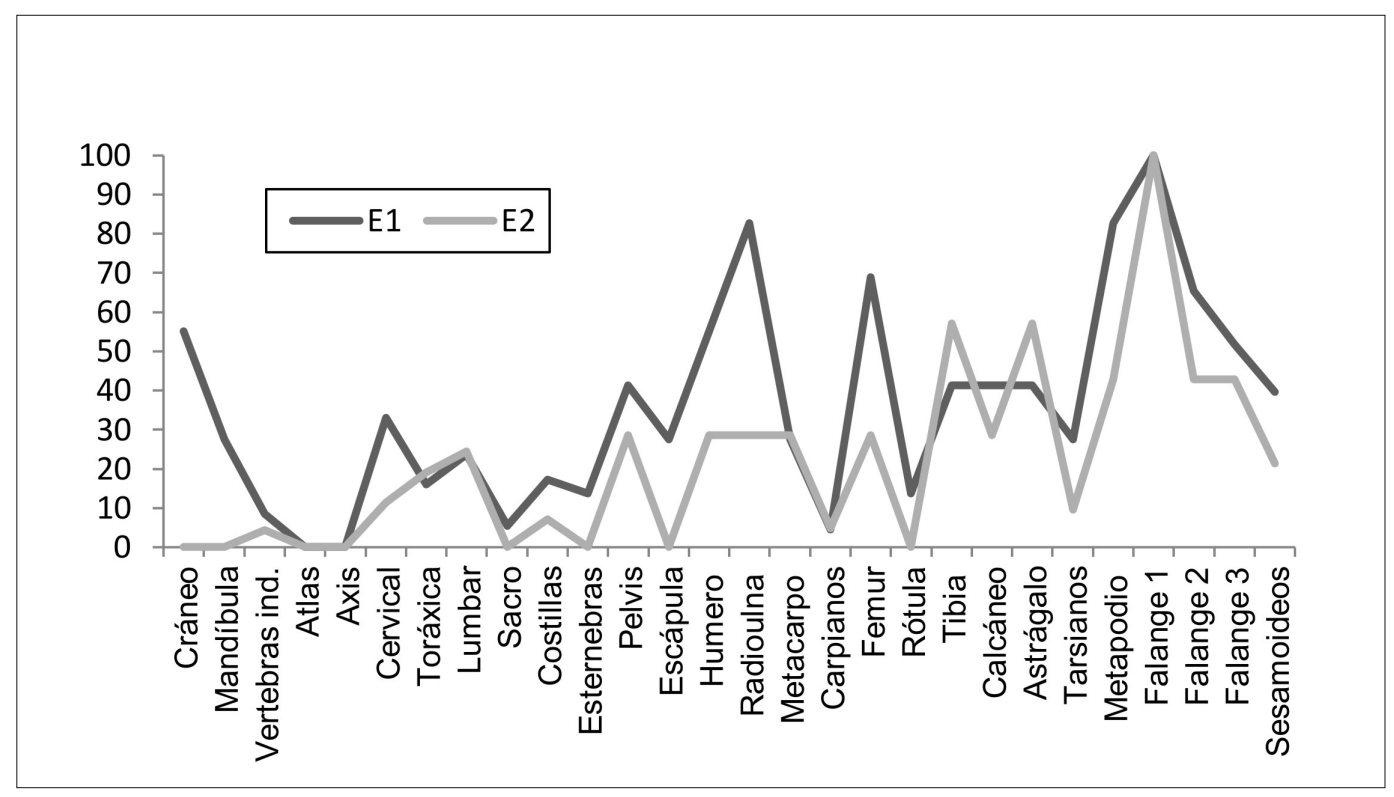

Figura 5. Representación de partes anatómicas de camélidos de CA, separado por estructura (\%MAU).

presentan una mayor frecuencia relativa. En la Figura 5 se observa que se repite el patrón notado previamente, con las falanges proximales como los elementos más representados para el esqueleto apendicular, aunque en esta ocasión le siguen en orden de importancia la tibia y el astrágalo. Sin embargo, una diferencia importante respecto al conjunto de Eı es que en el esqueleto axial notamos la ausencia de elementos de cráneo y mandíbula, siendo la pelvis la parte más representada, seguida en importancia por las vértebras lumbares y toráxicas. Por su parte, resulta interesante resaltar el hallazgo en este recinto de una columna articulada y casi completa de lo que aparenta ser, por el tamaño de las vértebras fusionadas, un ejemplar correspondiente a vicuña.

Por último, en los sondeos realizados en el Patio, sólo se han recuperado elementos correspondientes al esqueleto apendicular e incluyen tres naviculares, dos falanges primeras, dos metapodios y tres sesamoideos.

Para evaluar si estos resultados eran una función de la resistencia diferencial de los huesos a la atrición, aplicamos el análisis de correlación no paramétrico $r$ de Spearman, utilizando los valores de densidad ósea publicados por Stahl (1999). Obtuvimos resultados negativos (E1: -0,01643 para 38 pares de datos; E2: -0,2038 para 20 pares de datos) y no significativos (E1: 0,23611; E2: 0,27139, p. <0,05). Descartada la destrucción mediada por la densidad ósea en la configuración de los conjuntos, procedemos a comparar los valores de MAU\% con los índices de utilidad alimenticia o FUI (Food Utility Index) para Lama glama, publicados por Mengoni Goñalons (1991), con el fin de observar tendencias en cuanto a la utilización de los animales. Siguiendo la sugerencia de Marean y Frey (1997), este análisis se realizó por separado para los esqueletos apendicular y axial.

Los resultados fueron volcados en la Tabla 4. Allí podemos observar que solamente se obtuvo una correlación positiva y estadísticamente significativa para el esqueleto axial del conjunto arqueofaunístico de E2, quizás asociado a la ausencia de elementos con bajo rendimiento económico como el cráneo. El resto de las correlaciones arrojaron valores negativos y estadísticamente no significativos, indicando que las partes esqueletarias no habrían sido seleccionadas en función de su rendimiento en carne.

Una observación general que se deriva del análisis de los perfiles anatómicos de los conjuntos es que los mismos se destacan por presentar una mayor representatividad de los elementos con alto contenido en médula y bajo/ mediano en carne, en especial de falanges, radioulnas y 
tibias, seguidos en menor proporción por aquellos con alto contenido en carne pero bajo en médula, como vertebras y costillas. Dichos patrones parecen coincidir con lo que Yacobaccio y colaboradores (1997-1998) detectaron como asociados a bases residenciales de pastores actuales del área de Susques (Salta, Argentina). Allí, vincularon el énfasis en la selección de elementos con alto contenido en médula en bases residenciales con las técnicas de cocción implementadas (predominio del hervido versus el asado).

Perfil etario y número mínimo de individuos. En cuanto al perfil etario de las muestras analizadas, se presentan en primer lugar los resultados obtenidos de la clasificación de los ejemplares en solo tres clases de edad: nonato/neonato, juvenil y adulto, tomando como unidad de cuantificación al NISP. Se destaca que, sobre un total de 143 elementos recuperados en E1 con información sobre su estado de fusión, un 35,66\% (NISP 52) correspondería a restos fusionados o semifusionados mientras que el $63,64 \%$ (NISP 91) restante corresponde a ejemplares no fusionados. De estos últimos, el 70,33\% (NISP 64) correspondería a crías, determinados siguiendo los criterios de tamaño y características del tejido esponjoso (Reitz y Wing 2008). En el recinto E2, al ser menor la superficie excavada, la muestra de elementos con información sobre su estado de fusión se reduce $(n=35)$. No obstante, se puede advertir un incremento en la proporción de elementos fusionados 51,4\% $(n=18)$ en relación a los no fusionados $45,6 \%(n=17)$, respecto al conjunto anterior. Asimismo, entre los ejemplares no fusionados, tan solo dos especímenes corresponderían a crías.

Puesto que se ha señalado que la clasificación de los huesos en las categorías mencionadas tiende a distorsionar los resultados, generalmente subestimando la proporción de especímenes juveniles en relación a los adultos (Wheeler 1999), se procedió a calcular el MNI y a construir perfiles de sobrevivencia/mortalidad con objeto de comprobar la información recién proporcionada. De esta manera, el número mínimo de individuos (MNI) estimado para El es de cinco, pudiendo discriminarse dos individuos para los elementos fusionados y tres individuos para los no fusionados, mientras que tanto en E2 como en "Patio" se determinó la presencia de, al menos, dos individuos para cada conjunto, representados en ambos casos por un ejemplar para elementos fusionados y

\begin{tabular}{|l|l|l|}
\hline \multicolumn{1}{|c|}{ Recinto } & \multicolumn{1}{c|}{ Apendicular } & \multicolumn{1}{c|}{ Axial } \\
\hline E1 & $\begin{array}{l}\text { Rs }-0,1231 \\
p 0,73488\end{array}$ & $\begin{array}{l}\text { Rs }-0,1339 \\
p 0,73478\end{array}$ \\
\hline E2 & $\begin{array}{l}\text { Rs }-0,3698 \\
p 0,29292\end{array}$ & $\begin{array}{l}\text { Rs } 0,3426 \\
\text { p } 0,03602^{*}\end{array}$ \\
\hline
\end{tabular}

Tabla 4. Correlaciones entre \%MAU y Food Utility Index (FUI) para huesos no largos y largos en E1 y E2. Nota: ${ }^{*}$ p. <0,05.

otro para los no fusionados. Por último, en la Figura 6, se presentan los perfiles de mortalidad obtenidos para los conjuntos procedentes de las estructuras E1 y E2, compuestos de porcentajes de epífisis fusionados para seis categorías etarias.

Se puede observar, inicialmente, una tendencia similar entre ambos conjuntos, en la medida en que presentan una proporción relativamente alta de elementos correspondientes a individuos que habrían sido sacrificados o murieron antes del primer año de vida $(66,6 \%$ en E1 y 55,5\% en E2). No obstante, el patrón varía posteriormente, en la medida en que en E1 se observa una mayor tasa de sacrificio de animales a edades menores, con una baja proporción de animales sobreviviendo más allá del segundo (subadultos: 50\%) y tercer año de vida (adultos jóvenes: $54,5 \%$ ), y tan solo un $11 \%$ más allá de los 42 meses. En cambio, en E2 se registró una mayor cantidad de animales que habrían sobrevivido por más tiempo. De esta manera, todos aquellos animales que no fueron sacrificados durante el primer año, siguieron vivos hacia el segundo y tercer año de vida, con un $40 \%$ que sobrevivió más allá de los 42 meses (adultos). Por lo tanto, si bien se trata de un conjunto pequeño, podemos sostener como hipótesis, y basándonos en las diferentes metodologías empleadas, la presencia de una mayor proporción de individuos con elementos fusionados o sobreviviendo más tiempo respecto al subconjunto asignado a Camelidae de la Eı. Por último, cabe destacar que en el conjunto proveniente de "Patio" se observó únicamente la presencia de una falange proximal fusionada y un metapodio distal $\sin$ fusionar.

Marcas de procesamiento. La utilización a la cual fue sometido el subconjunto Camelidae también fue analizada a través de las huellas dejadas sobre los restos óseos como resultado del procesamiento de las carcasas. Las mismas han sido registradas en Eı tanto en el esqueleto apendi- 


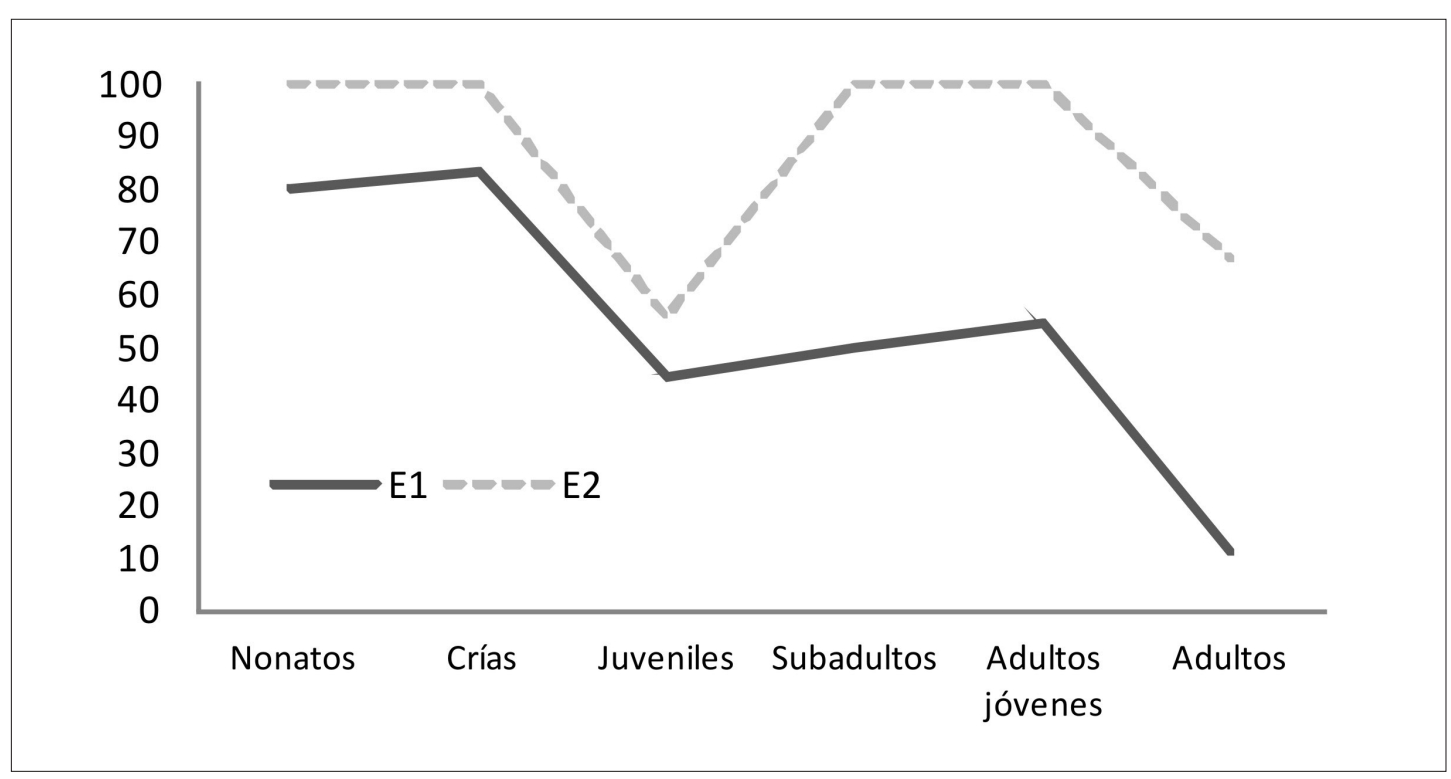

Figura 6. Perfiles de mortalidad derivados del porcentaje de epífisis fusionadas para cada clase de edad.

cular como en el axial, mientras que para E2 sólo se han encontrado en el esqueleto axial. En este último caso, se identificaron marcas de corte sobre el ilion, lo cual pudo haber resultado de la separación del sacro y la pelvis. Para el conjunto de Eı el registro es más variado. En cuanto al esqueleto axial, observamos huellas de corte sobre la cara lateral y medial de la rama de la mandíbula, como también sobre varias epífisis de vértebras cervicales. Por su localización, vinculamos las huellas mencionadas con la separación de los elementos ya citados de la cabeza. Asimismo, se identificaron huellas de corte y raspado sobre las porciones proximales de costillas, lo cual indicaría que se estarían llevando a cabo tareas de trozamiento secundario con el fin de reducir las carcasas en unidades menores (O'Connor 1993). Para el esqueleto apendicular, ubicamos la presencia de huellas de corte y machacado sobre fragmentos de diáfisis mediales de húmero, tibia y metapodio. Estas marcas pudieron haber tenido lugar durante la remoción de carne. También se observaron cortes sobre falanges proximales y un calcáneo, indicando el desmembramiento de las carcasas. En síntesis, el conjunto en general presenta una baja frecuencia de marcas de acción antrópica, sobre todo para E2, lo cual puede ser resultado de la alta fragmentación y evidencias de termoalteración de los conjuntos (ver infra). No obstante, para E1 observamos una gran diversidad de formas y tipos, lo que indicaría la realización de distintas activida- des vinculadas al procesamiento de los animales, como desarticulación y descarne.

Termoalteración. Con la finalidad de examinar el grado en que el conjunto fue expuesto al calor, se registró la coloración de los huesos (Mengoni Goñalons 1999). En la Tabla 5 se presenta el número de especímenes discriminados según su grado de alteración térmica. En la misma se puede observar que casi la mitad de los restos de camélidos (NISP 176) de E1 presenta alguna evidencia de termoalteración, principalmente en los estadios de carbonizado y calcinado. Teniendo en cuenta el contexto de recuperación de los mismos, asociados a un área de combustión de un fogón, es probable que hayan sido quemados como resultado de un patrón de descarte asociado a actividades de limpieza y mantenimiento del recinto. Alternativamente, los huesos pudieron ser empleados intencionalmente como material de combustión. Situación semejante parece haber operado sobre los conjuntos faunísticos de E2 y del Patio donde, si bien no han sido encontrados asociados a un fogón, una gran cantidad de huesos exhibe estadios avanzados de combustión, en lo que aparenta haber sido una práctica común en el descarte del material óseo.

Fragmentación del conjunto y patrones de fractura. Como mencionamos al principio de la sección de resultados, 
el grado de fragmentación del conjunto es alto, con 74\% de fragmentos menores a los $2 \mathrm{~cm}$. Este patrón se repite cuando consideramos aisladamente los restos asignados a camélidos. Si se omiten dientes sueltos y sesamoideos, el número de huesos completos asciende a 30 para E1 y 14 para E2, en su mayoría carpos, tarsos y falanges. Para el estudio de las fracturas nos limitamos a los huesos con cavidad medular (huesos largos, calcáneos y falanges proximal y medial). De los especímenes para los cuales pudo determinarse el estado del hueso al momento de fractura, observamos que en E1, 14 estaban secos y ocho frescos, siete de los cuales presentaban negativos o muescas de impacto sobre diáfisis, mientras que en E2, dos estaban secos y cuatro frescos con un negativo de impacto. Dichos negativos de impacto sobre las superficies de fractura de los huesos largos podrían estar indicando etapas de procesamiento final de las carcasas para consumo de médula.

\section{* Discusión}

En este trabajo se presentaron los resultados del análisis efectuado sobre el conjunto de restos óseos faunísticos recuperados en la excavación de dos estructuras y tres sondeos estratigráficos del sitio Corral Alto. El análisis contempló la evaluación de los efectos de diferentes procesos de formación del registro, un abordaje del conjunto óseo desde una perspectiva de tipo económica y un análisis de la distribución espacial de las distintas especies de camélidos en el sitio. A continuación repasaremos algunas de las consideraciones generales a las que arribamos y las vincularemos con su posible significación para la arqueología del Tardío regional.

En primer lugar hemos observado que, desde un punto vista taxonómico, la composición del conjunto óseo presenta una predominancia muy marcada de camélidos. A su vez, dentro de los especímenes que permitieron la asignación específica de estos recursos, se discriminó la presencia de Vicugna vicugna y Lama glama, con un predominio de las primeras sobre las segundas. Al respecto, cabe señalar que esta composición es coherente con lo establecido para numerosos sitios de la micro-región con cronologías asociadas a la ocupación del sitio (ca. 800-600 AP), donde se ha inferido que las actividades de caza habrían mantenido un rol importante en la economía de los grupos aún después de la adopción de estrategias productivas (Olivera y
Elkin 1994; Escola 1996, 2002; Urquiza y Aschero 2006; Grant 2008; Olivera y Grant 2008). Es decir, la combinación de actividades pastoriles y de caza, registradas a partir del análisis faunístico del sitio, se habría desarrollado dentro del marco de una economía caracterizada por el aprovechamiento de las aptitudes para la agricultura que ofrecían los sectores intermedios (Olivera y Vigliani 2000, 2002; López Campeny et al. 2005; Gasparotti y Escola 2012; Tchilinguirian y Olivera 2012; Escola et al. 2013), pero donde habría existido un fuerte énfasis en la explotación de camélidos dentro de una lógica que, si bien era básicamente pastoril, asignaba a la caza un rol primordial (Olivera y Vigliani 2000, 2002; Escola 2002; Urquiza y Aschero 2006; Grant 2008; Olivera y Grant 2008; Ortiz y Urquiza 2012).

Asimismo, y reforzando la evidencia de actividades de caza en el sitio, se ha registrado la presencia de una importante cantidad de puntas de proyectil. En este sentido, del total de artefactos formatizados analizados $(\mathrm{n}=111)$, recuperados tanto en las excavaciones de la Estructura $1(n=24)$ como de recolecciones superficiales en el denominado "Patio" ( $\mathrm{n}=87$ ), el $33 \%$ solamente corresponde a un único grupo tipológico, que es el de las

\begin{tabular}{|l|c|c|c|c|c|}
\hline Color & 0 & 1 & 2 & 3 & Total \\
\hline E1 & 201 & 25 & 71 & 80 & 377 \\
\hline E2 & 48 & 3 & 3 & 19 & 73 \\
\hline Patio & 1 & 2 & 1 & 6 & 10 \\
\hline
\end{tabular}

Tabla 5. Número de especímenes con o sin evidencias de termoalteración expresados en NISP. o: sin quemar; 1: quemado; 2 : carbonizado; 3: calcinado.

preformas y puntas de proyectil (enteras y fragmentadas) (Elías 2010). Consideramos que esta abultada frecuencia puede vincularse con la realización de actividades de caza sin dejar de tener presente también su posible asociación a tareas de defensa.

En otro orden de cosas, la información obtenida en este trabajo acerca de la explotación de camélidos permite inferir la realización de actividades domésticas que resultan coherentes con la hipótesis de la ocupación de una base residencial (Escola et al. 2013). En este sentido, hemos observado una alta diversidad de partes esqueletarias de camélidos, determinándose la presencia tanto del esqueleto axial como el apendicular para los recintos E1 y E2. 
En cambio, para "Patio" han sido recuperados muy pocos especímenes, estando presentes únicamente elementos provenientes del esqueleto apendicular. En cuanto a los dos primeros recintos, podemos mencionar que la alta diversidad de elementos registrados es esperable en bases residenciales con una alta estabilidad ocupacional, y parecería indicar la existencia de un aprovechamiento integral de las carcasas. A su vez, el elevado porcentaje de elementos caracterizados por presentar un alto contenido de médula y bajo de carne podría estar relacionada con las técnicas de cocción implementadas, orientadas principalmente al hervido de los huesos (Yacobaccio et al. 1997-1998). De esta manera, ambos recintos parecen haber tenido una funcionalidad parecida, siendo el escenario de actividades residenciales múltiples, vinculadas a prácticas de procesamiento y consumo de camélidos, con áreas de descarte y el uso de un fogón en E1.

Sin embargo, notamos una diferencia significativa entre ambos conjuntos. Mientras que en E1, con restos asignados tanto a vicuñas como a llamas, las carcasas parecen haber ingresado completas al recinto para su procesamiento y consumo, en E2, con solo vicuñas, no hemos registrado hasta el momento fragmentos correspondientes a cráneo y mandíbula. Aun teniendo en cuenta el sesgo presente respecto a la extensión de las excavaciones, este último resultado nos permite sostener como hipótesis que los restos obtenidos mediante actividades de caza habrían sido ingresados al sitio luego de un procesamiento inicial de trozamiento en otro lugar, mientras que los restos de animales domesticados habrían entrado enteros a El. Cabe agregar también la posibilidad de que la ausencia de partes de bajo valor calórico, como el cráneo, pueda asociarse a su utilización en actividades de tipo ritual ceremonial (Urquiza et al. 2013). Por su parte, independientemente de la condición de silvestre o domesticado del recurso Camelidae explotado, observamos la misma estructura de selección de partes anatómicas en ambos recintos, con un predominio de elementos de alto contenido en médula, seguido por aquellos con alto contenido en carne. Vinculamos dicho patrón con el empleo de similares técnicas de preparación de los alimentos, con un predominio del hervido sobre el asado.

En este contexto, el reducido tamaño de los huesos recuperados en las estructuras y sondeos excavados, sumado al elevado índice de fragmentación de los es- pecímenes, puede ser interpretado como el resultado de eventos periódicos de limpieza. Esto nos lleva a pensar que los recintos, sobre todo E1 y E2, habrían sido áreas de habitación. Los fragmentos de pequeño tamaño conservados en el sedimento serían, por lo tanto, la consecuencia de su enterramiento producto del pisoteo en una matriz arenosa, implicando que los materiales de descarte de mayor tamaño serían trasladados a basureros externos a los recintos. A su vez, estas características parecen ser concordantes con un importante grado de procesamiento sufrido por los restos óseos faunísticos, lo que sumado al elevado porcentaje de restos óseos con evidencias de alteración térmica y la presencia de una estructura de combustión en Eı, reflejarían una significativa actividad cultural llevada a cabo dentro de estas estructuras. En el caso de "Patio", la poca cantidad de hallazgos recuperados en los sondeos, junto al tamaño pequeño de los especímenes óseos, estaría dando cuenta de una probable área de circulación, con escaso depósito de material.

En cuanto a la estructura etaria, se han registrado distintas tendencias según el recinto analizado. Para el subconjunto Camelidae de E1 se constató un predominio de individuos sacrificados antes de alcanzar la madurez osteológica, mientras que para E2 se observó una mayor cantidad de animales que habrían sobrevivido más allá de los 42 meses de edad. Resulta interesante recordar que en la primera estructura hemos determinado la presencia de camélidos tanto domesticados como silvestres, mientras que para la segunda, sólo se ha registrado la presencia de animales de caza. Si bien es preciso tener en cuenta que esta última no ha sido excavada en su totalidad, con los problemas de sesgo que esto puede acarrear al intentar establecer comparaciones, la similitud en cuanto a la funcionalidad asignada a ambos recintos nos permite arribar a ciertas interpretaciones respecto a los perfiles etarios, las que requerirán de la ampliación de las excavaciones en futuras investigaciones para su contrastación.

En este sentido, los datos hasta ahora disponibles para Antofagasta de la Sierra han permitido sostener que, durante el lapso ca. 2500-1000 años AP, dominarían los ejemplares juveniles sobre los adultos, mientras que a partir de ca. 1200-1000 años AP aumentaría la representación de los individuos adultos en las muestras (Olivera 1997; Olivera y Vigliani 2000, 2002; Olivera y Grant 
2008; Ortiz y Urquiza 2012). A partir de estos perfiles etarios, se ha planteado que durante el primer lapso (Formativo) se mantendrían rebaños más pequeños manejados a nivel de unidad familiar en los que habría dominado un morfotipo de llama (Intermedio), orientado a un uso más generalizado para carne, fibra y transporte. Esto habría obligado al sacrificio de mayor cantidad de individuos machos al llegar su edad reproductora (mayor a dos años) para evitar el desbalance en el rebaño. A partir de alrededor de 1300/1000 años AP (Tardío) habría comenzado a producirse una especialización en el manejo de los rebaños, llevando a diferenciar morfotipos más específicos para transporte y fibra, lo que llevaría hipotéticamente al mantenimiento de los animales hasta edades mayores (Olivera 1997; Olivera y Vigliani 2000, 2002; Olivera y Grant 2008).

Dentro de este marco, resulta interesante analizar más detalladamente los resultados obtenidos para la arqueofauna de Corral Alto. Si correlacionamos los datos de los perfiles etarios de cada estructura junto con la determinación interespecífica de camélidos, observamos que en E2 el predominio de adultos se vincula a la presencia de animales obtenidos únicamente mediante la caza, mientras que en Eı la presencia de animales domésticos junto con los silvestres resulta en un aumento en la proporción de individuos juveniles. Por lo tanto, las proporciones más altas de animales juveniles o con elementos no fusionados podrían ser interpretadas como resultado del manejo de rebaños pequeños para una explotación generalizada, mientras que el incremento de restos asignados a individuos adultos podría corresponder a un perfil generado a partir de la obtención de recursos mediante la caza. De esta manera, el manejo de animales domesticados inferido parece mostrar una continuación con los patrones registrados a nivel de unidades familiares en sitios formativos del área de estudio y diferenciarse de los cambios asociados a momentos tardíos. Si bien se observa un leve incremento en la proporción de individuos con elementos fusionados respecto a los conjuntos del Formativo, no deja de ser significativo el hecho de que los restos asignados a individuos adultos podrían corresponder en mayores proporciones a recursos obtenidos mediante la caza.

En relación a esta última interpretación, es interesante mencionar que en sitios de ocupación temporaria y ac- tividades específicas de quebradas de altura, tales como Real Grande 6, con ocupaciones asignadas también al período Tardío y donde sólo se han detectado restos asignados a vicuñas, se ha observado patrones etarios similares al registrado en E2. Esto último, por lo tanto, permite sostener la hipótesis de que dicho perfil respondería a la explotación de animales obtenidos mediante la caza y no al manejo de recursos de rebaños (Grant 2014). No obstante, cabe destacar que el procesamiento al que se vieron sometidos los recursos silvestres en ambos sitios muestra patrones diferentes, producto de la diferente funcionalidad asignada a los mismos. En este sentido, mientras que en Corral Alto las vicuñas pudieron haber sido ingresadas luego de su trozamiento inicial en otro lugar, observándose un predominio de los eventos de procesamiento, consumo y descarte sobre los egresos de partes esqueletarias, en Real Grande 6 se registró que, si bien carcasas enteras habrían sido ingresadas en el sitio, partes anatómicas de alto rendimiento económico habrían sido removidas para su consumo diferido en otro lugar (Grant 2014). Estos últimos patrones de procesamiento permiten reforzar la idea que el sitio analizado en este trabajo habría funcionado como una base residencial de ocupación permanente, mientras que Real Grande habría funcionado, durante el período Tardío, como un puesto temporario dedicado al desarrollo de actividades especializadas orientadas a la obtención y procesamiento a gran escala de recursos silvestres (Grant 2014).

Por su parte, ciertos datos contextuales apuntan a identificar diferencias en las características de Corral Alto respecto a los patrones detectados en los sitios de fondo de cuenca asignados cronológicamente a momentos del período Tardío.

Al respecto, en cuanto a la producción lítica, Elías (2010) ha registrado, a través del análisis de las materias primas utilizadas en sitios tardíos del fondo de cuenca, una tendencia hacia el predominio de recursos líticos cuyos afloramientos se hallan a menos de $2 \mathrm{~km}$ desde los asentamientos (recursos muy inmediatos), lo que ha relacionado con una mayor importancia del componente agrícola en su subsistencia y una menor movilidad hacia otros sectores de la cuenca. Dicha interpretación ha sido confirmada por recientes análisis isotópicos sobre colágeno óseo de camélidos de una base residencial del fondo de cuenca (Bajo del Coypar II), que mostrarían una 
reducción en la movilidad de los rebaños, los cuales habrían permanecido durante todo el ciclo anual en dicho sector, complementando su dieta mediante forraje artificial (Grant 2014). Sin embargo, la mencionada reducción en la movilidad no ha quedado en evidencia a partir de la información resultante del estudio del registro lítico recuperado en Corral Alto, destacándose un importante aprovechamiento de recursos inmediatos (entre 2 y $5 \mathrm{~km}$ ) y locales (entre 5 y $40 \mathrm{~km}$ ) - procedentes de diversos microambientes de la cuenca de Antofagasta de la Sierra- así como también de recursos no locales. Esto ha llevado a Elías (2010) a sugerir, para los grupos tardíos que ocuparon Corral Alto, una mayor movilidad dentro de la cuenca en comparación a sus contemporáneos del fondo de cuenca. Esta situación se hace extensiva también, dentro de los sectores intermedios, a los grupos tardíos que habitaron la quebrada del río Las Pitas (sitios Punta de la Peña 9. III y Peñas Coloradas 3 cumbre) los cuales, si bien mantuvieron desde momentos previos un uso importante de recursos líticos inmediatos, esto se vio complementado por una recurrente utilización de recursos inmediatos, locales y no locales (Somonte y Cohen 2006; López Campeny 2010; Escola et al. 2014).

Asimismo, los resultados faunísticos obtenidos en este trabajo permiten sostener que, a diferencia del agropastoralismo a gran escala practicado en el fondo de cuenca, en el sector intermedio de la quebrada de Miriguaca se habría mantenido una economía agrícola pastoril diversificada. Por un lado, la presencia de contenedores aptos para el almacenamiento, la identificación de numerosos morteros dentro del sitio y la localización de una posible red de riego en las proximidades serían indicativos de la realización de prácticas agrícolas en pequeña escala (Gasparotti y Escola 2012). Por otro lado, ha quedado en evidencia que el pastoreo de pequeños rebaños de llamas habría sido acompañado por prácticas de aprovisionamiento de recursos silvestres (vicuñas). El papel destacado cumplido por las actividades de caza, inferido a partir de la alta frecuencia relativa de vicuñas registradas, puede ser visto como resultado de una estrategia activa de diversificación económica que permitiría a los pastores amortiguar los efectos negativos asociados al riesgo de mantener rebaños pequeños en ambientes inestables como los puneños (Escola 1996). De esta manera, los grupos asentados en Corral Alto habrían complementado las prácticas pastoriles con la adquisición de recursos silvestres permitiéndoles incrementar la diversidad de las especies explotadas. Esta estrategia permitiría explotar a los animales domesticados para una variedad de funciones económicas y no únicamente para obtener carne. Una situación similar a la de Corral Alto ha sido hallada en sitios tardíos ubicados en otros sectores intermedios, más específicamente en la cuenca media del río Las Pitas, donde la economía de estos grupos ha sido caracterizada como mixta, con pastoreo de camélidos y mantenimiento de la caza y recolección, si bien las composiciones específicas de los conjuntos varían (Urquiza y Aschero 2006; Urquiza 2009; Ortiz y Urquiza 2012).

En síntesis, la información recabada hasta ahora para la micro-región de Antofagasta de la Sierra permite sostener que, durante el período Tardío y en ciertos sectores del área de estudio, tales como fondo de cuenca y quebradas de altura, se habrían desarrollado estrategias económicas que apuntarían a la maximización en la obtención de productos. La explotación especializada de rebaños para obtener fibras y animales cargueros junto con el incremento de los productos obtenidos mediante la caza, podrían haberse convertido en elementos importantes para el intercambio y para facilitar la interacción social en un contexto caracterizado por intercambio inter-regional, elites emergentes, tributos o múltiples combinaciones, cuando la región se integró a la economía política más amplia de los Andes centro-sur (Grant 2014). Sin embargo, esta nueva organización económica parece haber funcionado en simultáneo junto con las tradicionales estrategias económicas diversificadas llevadas a cabo a pequeña escala (prácticas agrícolas y explotación generalizada de camélidos, tanto silvestres como domésticos), como las detectadas en el sitio Corral Alto, en el sector intermedio del río Miriguaca. Esto sugeriría la continuación de un modo de producción doméstico o cooperativo interfamiliar en algunos sectores de las quebradas intermedias, en consonancia con lo planteado por otros investigadores (Martel y Aschero 2007; Escola et al. 2013; Elías 2014). En este sentido, cabe recordar que Martel y Aschero (2007) sugieren que, con posterioridad a 1100 años AP, el desarrollo de grupos orientados a actividades agrícolas extensivas y al control políticoreligioso en el fondo de cuenca no habría necesariamente implicado la desaparición de los ejes económicos interfamiliares pastoriles en los sectores intermedios de dicha cuenca. 


\section{* Conclusiones}

El análisis del conjunto faunístico de Corral Alto ha permitido determinar la existencia de diversas estrategias implementadas por los habitantes de este sitio durante parte del período Tardío.

Por un lado, la identificación de animales domesticados permite plantear la persistencia de un manejo pastoril dirigido a la explotación integral del recurso Camelidae, focalizada en la obtención generalizada de diversos productos (carne, fibra y en menor medida transporte). Por otra parte, la determinación de especímenes asignados a vicuñas indicaría la existencia de estrategias dirigidas a la caza de animales silvestres, confirmando lo planteado por diversas investigaciones respecto a la importancia de las mismas hasta momentos tardíos del desarrollo sociocultural del área de estudio (Elkin y Olivera 1994; Olivera 1997; Escola 2002; Urquiza y Aschero 2006; Olivera y Grant 2008; Ortiz y Urquiza 2012). Sin embargo, resulta importante tomar en cuenta que en la mayoría de los especímenes no fue posible la identificación sistemática más allá del nivel de familia, por lo cual los perfiles anatómicos se han calculado sin discriminar entre animales silvestres y domésticos. Aun así, la presencia/ausencia de restos asignados a animales domésticos en diferentes recintos nos ha permitido generar hipótesis respecto al manejo de los recursos. De esta manera, hemos planteado para este sitio, ubicado en un sector intermedio de la cuenca de Antofagasta de la Sierra, cierta continuidad en el manejo de los recursos de rebaño a la manera de las sociedades agropastoriles tempranas, marcando una diferencia con los patrones observados para los sitios tardíos de fondo de cuenca y quebradas de altura.

De este modo, los resultados presentados apuntan a mostrar a Corral Alto como un sitio residencial de ocupación prolongada o permanente, donde se desarrollaron múltiples actividades vinculadas a prácticas de procesamiento y consumo de camélidos. En este sentido, esta ocupación localizada en los sectores intermedios de la cuenca reflejaría la continuación de un modo de producción doméstico o cooperativo interfamiliar (Martel y Aschero 2007; Elías 2014), dirigido a la autosuficiencia económica y apartado de los procesos económicos tardíos tendientes a la maximización en la obtención de productos.

Estas evidencias nos obligan a profundizar en los modelos hasta ahora presentados en cuanto al manejo y uso de recursos faunísticos por las sociedades agropastoriles del Tardío, dejando abierta la posibilidad de una mayor variabilidad en los patrones según los sitios y sectores analizados de lo que se creía hasta el momento. Esto lleva a plantear nuevos interrogantes que quedarán abiertos a próximas investigaciones en la micro-región.

En síntesis, esperamos haber demostrado en este trabajo cómo el análisis de la fauna de sitios arqueológicos puede ayudar a comprender distintos aspectos de la vida de las comunidades del período Tardío, así como también enriquecer la discusión teórica respecto a los alcances de los modelos de ocupación del espacio vigentes en el área de estudio.

\section{* Referencias citadas}

ASCHERO, C. 2000. Figuras humanas, camélidos y espacios en la interacción circumpuneña. En Arte en las rocas. Arte Rupestre, Menhires y Piedras de colores en la Argentina, M. Podestá y M. de Hoyos (Eds.), pp. 15-44. Sociedad Argentina de Antropología y Asociación Amigos del INAPL, Buenos Aires.

BARONE, R. 1987. Anatomía comparada de los mamiferos domésticos (I) Osteología. Editorial Hemisferio Sur, Buenos Aires.

BEHRENSMEYER, A. K. 1978. Taphonomic and ecological information from bone weathering. Palaeobiology 4: 150-162.

BELOTTI LÓPEZ DE MEDINA, C. 2013. Usos económicos y rituales de la fauna en la región valliserrana del Noroeste Argentino entre los inicios del periodo temprano y hasta la Conquista inka (ca. 600 ac - $1600 \mathrm{dc}$ ): zooar- queología del valle de yocavil (Catamarca), centro y norte del valle calchaquí (salta) y la quebrada de Humahuaca (Jujuy). Tesis Doctoral. Facultad de Filosofía y Letras, Universidad de Buenos Aires, Buenos Aires.

BINFORD, L. 1984. Faunal Remains from Klasies River Mouth. Academic Press, Orlando.

BRAIN, C. K. 1981. The Hunters or the Hunted? The University of Chicago Press, Chicago.

COHEN, L. 2005. Entre guano y arena...Ocupaciones recurrentes: un caso de estudio en el sitio Punta de la Peña 9-III Antofagasta de la Sierra, Catamarca. Trabajo final de la carrera de Arqueología, Facultad de Ciencias Naturales e Instituto Miguel Lillo, Universidad Nacional de Tucumán, Tucumán. 
2011. Prácticas sociales, estrategias de visibilidad y construcción de la cartografía social durante el lapso ca. 1000-1500 AD en Antofagasta de la Sierra, Catamarca. Perspectivas desde el sitio Peñas Coloradas 3 Cumbre. Tesis Doctoral inédita. Facultad de Filosofía y Letras, Universidad de Buenos Aires, Buenos Aires.

2014. Miradas desde y hacia los lugares de poder. Antofagasta de la Sierra entre 1000 y 1500 DC. Arqueología 20(1): 47-62. https://sites.google.com/site/reviarqueol/4home/arqueologa-20-1-2014

DANTAS, M. 2012. Identificación interespecífica de camélidos en el valle de Ambato (Catamarca, Argentina). Una aproximación a la problemática desde distintas líneas de análisis. Revista del Museo de Antropología 5(1): 259-268.

DAVIS, S. 1989. La Arqueología de los Animales. Ediciones Bellaterra, Barcelona.

ELÍAS, A. M. 2010. Estrategias tecnológicas y variabilidad de los conjuntos líticos de las sociedades tardías en Antofagasta de la Sierra (Provincia de Catamarca, Puna Meridional Argentina). Tesis Doctoral inédita. Facultad de Filosofía y Letras, Universidad de Buenos Aires, Buenos Aires.

2014. Técnicas líticas diversas entre las sociedades de Antofagasta de la Sierra (Provincia de Catamarca, Puna Meridional Argentina) posteriores a ca. 1100 a.p. Estudios Atacameños 47: 59-82.

ELKIN, D. 1996. Arquezoología de Quebrada Seca 3: Indicadores de subsistencia humana temprana en la Puna Meridional Argentina. Tesis Doctoral inédita. Facultad de Filosofía y Letras, Universidad de Buenos Aires, Buenos Aires.

ELKIN, D., C. M. MADERO, G. L. MENGONI GOÑALONS, D. E. OLIVERA y H. D. YACOBACCIO. 1991. Avances en el estudio arqueológico de los camélidos del Noroeste Argentino. En Actas de la VII Convención Internacional de Especialistas en Camélidos Sudamericanos, Jujuy. Ms.

ESCOLA, P. 1996. Riesgo e incertidumbre en economías agropastoriles: consideraciones teórico-metodológicas. Arqueología 6: 9-24.

2002. Caza y pastoralismo: un reaseguro para la subsistencia. Relaciones de la Sociedad Argentina de Antropología XXVII: 233- 245.

ESCOLA, P. S., S. HOCSMAN y S. LÓPEZ CAMPENY. 2014. Artefactos líticos y variabilidad de asentamientos en contextos agro-pastoriles de Antofagasta de la Sierra (Catamarca, Argentina). En Artefactos Líticos, Movilidad y Funcionalidad de Sitios en Sudamérica: Problemasy Perspectivas, P. Escola y S. Hocsman (Eds.), pp. 41-57. Archaeopress, Oxford.
ESCOLA, P. S., S. LÓPEZ CAMPENY, A. R. MARTEL, A. S. ROMANO, S. HOCSMAN y C. SOMONTE. 2013. Re-conociendo un paisaje. Prospecciones en la quebrada de Miriguaca (Antofagasta de la Sierra, Catamarca). Andes, Antropología e Historia 24: 397-423.

FLORES OCHOA, J. A. 1982. Causas que originaron la actual distribución espacial de las Alpacas y Llama. En Senri Tthological Studies, 10, L. Millones y H. Tomoeda (Eds.), pp. 63-92. National Museum of Ethnology, Osaka.

GALOTTA, D. y J. GALOTTA. 1988. Esqueleto de la llama (Lama glama guanicoe f. d. glama Linnaeus, 1978). Revista de Ciencias Agrarias y Tecnología de Alimentos 9(1-4): 19-61.

GASCO, A. 2013. Caza y Pastoreo de camélidos en la frontera meridional del "mundo" andino. Una aproximación osteométrica. Tesis Doctoral inédita. Universidad Nacional de Córdoba, Córdoba.

GASPAROTTI, L. y P. ESCOLA. 2012. Elecciones tecnológicas en la alfarería. Abordaje preliminar de la cerámica de Corral Alto, Antofagasta de la Sierra (Catamarca). La Zaranda de Ideas 8(1): 49-64.

GRANT, J. 2008. El recurso Camelidae en sitios de la Puna Meridional Argentina: un aproximación osteométrica. Tesis de Licenciatura inédita. Universidad de Buenos Aires, Facultad de Filosofía y Letras, Universidad de Buenos Aires, Buenos Aires.

2010. Aportes de distintas técnicas osteométricas para la identificación interespecífica de camélidos sudamericanos. En Zooarqueología a Principios del Siglo XXI. Aportes Teóricos, Metodológicos y Casos de Estudio, M. Gutiérrez, M. de Nigris, P. Fernández, M. Giardina, A. Gil, A. Izeta, G. Neme y H. Yacobaccio (Eds.), pp. 17-28. Ediciones del Espinillo, Buenos Aires.

2014. Manejo económico de camélidos en Antofagasta de la Sierra (Puna Meridional Argentina): una aproximación zooarqueológica $e$ isotópica. Tesis Doctoral inédita. Facultad de Filosofía y Letras, Universidad de Buenos Aires, Buenos Aires.

IZETA, A. 2007. Zooarqueología del sur de los valles Calchaquíes (Provincias de Catamarca y Tucumán, República Argentina). British Archaeological Reports, Oxford.

IZETA, A., URQUIZA, S. BALDINI y L. BALDINI. 2009. La arqueofauna del período Tardío en el NOA. Una aproximación desde los conjuntos del sitio Molinos I (provincia de Salta, R. Argentina). Arqueología 15: 63-84.

KAUFMANN, C. 2009. Estructura de Edady Sexo en Guanaco: Estudios Actualísticos y Arqueológicos en Pampa y Patagonia. Sociedad Argentina de Antropología, Buenos Aires. 
KENT, J. D. 1982. The Domestication and Exploitation of the South American Camelids: Methods of Analysis and Their Application to Circum-Lacustrine Archaeological Sites in Bolivia and Peru. Tesis Doctoral inédita. Washington University-St. Louis, University Microfilms, St. Louis.

KLEIN, R.G. y K. CRUZ-URIBE. 1984. The Analysis of Animal Bones from Archaeological Sites. University of Chicago Press, Chicago.

LÓPEZ, G. 2003. Pastoreo y caza de camélidos en el Temprano de la Puna de Salta: Datos osteométricos del sitio Matancillas 2. Intersecciones en Antropología 4: 17-27.

LÓPEZ CAMPENY, S. 2010. De un hogar en la Puna... Relatos de idas y vueltas. En El Hábitat Prehispánico. Arqueología de la Arquitectura y de la Construcción del Espacio Organizado, M. E. Albeck, C. Scattolin y M. A. Korstanje (Eds.), pp. 215-242. Editorial de la Universidad Nacional de Jujuy, Jujuy.

LÓPEZ CAMPENY, S., D. OLIVERA, V. FERNÁNDEZ VARELA y J. PEÑA. 2005. Procesos tafonómicos, subsistencia y uso del espacio: análisis de la arqueofauna de un sitio agropastoril de la Puna Meridional Argentina (Punta de la Peña 9, Antofagasta de la Sierra, Catamarca). Intersecciones en Antropología 6: 1-28.

LYMAN, R. 1994. Vertebrate Taphonomy. Cambridge University Press, Cambridge.

MAREAN, C.W. y C. J. FREY. 1997. The animal bones from caves to cities: reverse utility curves as methodological artifacts. American Antiquity 62: 698-711.

MARTEL, A. 2009. Arte rupestre: construcción y significación del espacio en la Puna meridional argentina (Antofagasta de la Sierra, Catamarca). En Crónicas sobre la Piedra. Arte Rupestre de las Américas, M. Sepúlveda, L. Briones y J. Chacama (Eds.), pp. 271280. Andros Impresores. Santiago de Chile.

MARTEL, A. y C. ASCHERO. 2007. Pastores en acción: imposición iconográfica vs. Autonomía temática. En Producción y circulación prehispánicas de bienes en el Sur Andino, A. Nielsen, M.C. Rivolta, V. Seldes, M.M. Vázquez y P. Mercolli (Eds.), pp. 329349. Editorial Brujas, Córdoba.

MARTEL, A. y P. S. ESCOLA. 2011. Bloques y Arte Rupestre en la Quebrada de Miriguaca (Depto. Antofagasta de la Sierra, Catamarca, Argentina). Boletín del SIARB 25: 84-92.

MEADOW, R. 1987. Techniques for comparing bone measerument data from small simples. Paper presented at the Northeastern Faunal Analysis Conference. Storrs, Connecticut.

1999. The use of index scaling techniques for research on ar- chaeozoological collections from the Middle East. En Historia animalium ex ossibus. Beiträge zur paläoanatomie, archäologie, ägyptologie, ethnologie und geschichte der tiermedicin. Festschrift für Angela von den Driesch, C. Becker, H. Manhart, J. Peters y J. Schibler (Eds.), pp. 285-300. Verlag Marie Leidorf GmbH, Rahden.

MENEGAZ, A.N., F. GOIN, C. SALEMME y E. ORTIZ JAUREGUIZAR. 1988. Una propuesta de sistematización de los caracteres morfométricos de los metapodios y falanges de Camelidae. En De Procesos, Contextos y otros Huesos, N. Ratto y A. Haber (Eds.), pp. 53-64. Instituto de Ciencias Antropológicas (FFyLUBA), Buenos Aires.

MENGONI GOÑALONS, G. L. 1991. La llama y sus productos primarios. Arqueología 1: 179-196.

1999. Cazadores de guanacos de la estepa patagónica. Sociedad Argentina de Antropología, Buenos Aires.

2001. Variabilidad de la anatomía económica en la llama. En El uso de los camélidos a través del tiempo, G. L. Mengoni Goñalons, D. E. Olivera y H. D. Yacobaccio (Eds.), pp. 145-153. Ediciones del Tridente, Buenos Aires.

2007. Camelid management during Inca times in N. W. Argentina: models and archaeozoological indicators. Anthropozoologica 42(2): 129-141.

2008. Camelids in ancient Andean societies: A review of the zooarchaeological evidence. Quaternary International 185: 59-68.

MENGONI GOÑALONS, G. L. y H. D. YACOBACCIO. 2006. The domestication of South American camelids. A view from the South-Central Andes. En Documenting domestication. New Genetic and Archaeological Paradigms, M. A. Zeder, D. G. Bradley, E. Emshwiller y B. D. Smith (Eds.), pp. 228-244. University of California Press, California.

MERCOLLI, P. 2010. Estrategias de subsistencia en la Quebrada de Humahuaca, provincia de Jujuy. Dos casos de estudio relacionados al manejo ganadero y la trascendencia de la caza a través del tiempo en las sociedades humanas. En Zooarqueología a Principios del Siglo XXI. Aportes Teóricos, Metodológicos y Casos de Estudio, M. Gutiérrez, M. de Nigris, P. Fernández, M. Giardina, A. Gil, A. Izeta, G. Neme y H. Yacobaccio (Eds.), pp. 273-84. Ediciones del Espinillo, Buenos Aires.

O'CONNOR, T. 1993. Process and terminology in Mammal Carcass Reduction. International Journal of Osteoarchaeology 3: 63-67.

OLIVERA, D. 1992. Tecnología y estrategias de adaptación en el Formativo (Agro-Alfarero Temprano) de la Puna Meridional Argentina. Un caso de estudio: Antofagasta de la Sierra (pcia. De Catamarca, R.A.). Tesis 
Doctoral inédita. Universidad Nacional de la Plata, La Plata.

1997. La importancia del recurso Camelidae en la Puna de Atacama entre los 10.000 y 500 años A.P. Estudios Atacameños (Tomo Especial dedicado al II Taller Binacional de Interacción entre el NOA y el Norte Chileno) 14: 29-41.

2001. Perfil etario y rendimiento económico de Lama glama. En El uso de los camélidos a través del tiempo, G. L. Mengoni Goñalons, D. E. Olivera y H. D. Yaccobaccio (Eds.), pp. 179-2O2. Grupo Zooarqueología de Camélidos, Buenos Aires.

OLIVERA, D. E. y D. C. ELKIN. 1994. De cazadores y pastores: El proceso de domesticación de camélidos en la Puna Meridional Argentina. En Zooarqueología de camélidos, 1, D. C. Elkin, C. Madero, G. L. Mengoni Goñalons, D. E. Olivera, M. C. Reigadas y H. D. Yacobaccio (Eds.), pp. 95-124. Grupo de zooarqueología de camélidos, Buenos Aires.

OLIVERA, D. E. y M. DE AGUIRRE. 1995. Arqueología aplicada a la reactivación de sistemas agrícolas prehispánicos: el aporte interdisciplinario. Hombre y Desierto (Actas del XI Congreso de Arqueología Chilena) 9:337-349.

OLIVERA, D. E. y S. VIGLIANI. 2000-2002. Proceso cultural, uso del espacio y producción agrícola en la Puna Meridional Argentina. Cuadernos del Instituto Nacional de Antropología y Pensamiento Latinoamericano 19: 459-481.

OLIVERA, D. E. y J. GRANT. 2008. Economía y ambiente durante el Holoceno Tardío (ca. 4500-400) de Antofagasta de la Sierra (Puna Meridional Argentina). En Temas de Arqueología. Estudios tafonómicos y zooarqueológicos, I, A. Acosta, D. Loponte y L. Mucciolo (Eds.), pp. 99-131, Buenos Aires.

OLIVERA, D. E., A. ELÍAS, P. SALMINCI, P. TCHILINGUIRIAN, L. GRANA, J. GRANT y P. MIRANDA. 2008. Nuevas evidencias del proceso sociocultural en Antofagasta de la Sierra. Informe de campaña año 2007. La Zaranda de Ideas 4: 119-140.

ORTIZ, J y S. URQUIZA. 2012. Zooarqueología y tafonomía del Período Tardío-Inca en Peñas Coloradas, Antofagasta de la Sierra (Puna de Catamarca, Argentina). Revista del Museo de Antropología 5: 245-258.

PACHECO TORRES, V. R., ALTAMIRANO ENCISO, A. y GUERRA PORRAS, E. 1986. The Osteology of South American Camelids. Archaeological Research Tools, Vol. 3. Institute of Archaeology. University of California, Los Angeles.

PRATOLONGO, G. 2008. Estudio de los restos faunísticos de dos sitios tardíos en el valle de Yocavil, provincia de Catamarca: Rincón Chico 15 y Las Mojarras. En Estudios arqueológicos en Yocavil,
M. N. Tarragó y L. R. González (Eds.), pp. 81-126. Asociación de Amigos del Museo Etnográfico, Buenos Aires.

PODESTÁ, M. y D. OLIVERA. 2006. El contexto ecológico y económico del arte rupestre en la arqueología de la Puna Meridional Argentina. En Kay Pacha. Cultivating earth and water inthe Andes, P. Dransart (Ed.), pp. 137-149. Archaeopress, Oxford.

RAVIÑA, M., A. M. FERNÁNDEZ y A. CAPPARELLI. 2007. La relación de las tarabitas, horquetas o ganchos de atalaje con el tráfico de bienes en momentos tardíos prehispánicos. Estudios Atacameños 33: 87-104.

REIGADAS, M. C. 2008. Explotación de recursos animales y explotación textil durante el Holoceno en Antofagasta de la Sierra. Estudios Atacameños 35: 35-48.

REITZ, E. J. y E. S. WING. 2008. Zooarchaeology. Cambridge University Press, Cambridge.

RUSSELL, N. 2012. Social zooarchaeology: humans and animals in prehistory. Cambridge University Press, New York.

SALMINCI, P. 2012. Espacios Residenciales y Productivos. El Paisaje Arqueológico de Antofagasta de la Sierra entre los Siglos XI y XVI D.C. Tesis Doctoral inédita. Facultad de Filosofía y Letras, Universidad de Buenos Aires, Buenos Aires.

SOMONTE, C. y M. L. COHEN. 2006. Reocupación y producción lítica: un aporte a la historia ocupacional de los recintos 3 y 4 sitio agropastoril de Punta de la Peña 9- Sector III (Antofagasta de la Sierra, Catamarca, Argentina). Werken 9: 135-158.

STAHL, P.W. 1999. Structural density of domesticated South American camelid skeletal elements and the archaeological investigation of prehistoric Andean ch'arki. Journal of Archaeological Science 26: 1347-1368.

TCHILINGUIRIAN, P. 2008. Paleoambientes Holocenos en la Puna Austral, Provincia de Catamarca $\left(27^{\circ}\right.$ S): Implicancias Geoarqueológicas. Tesis Doctoral inédita. Facultad de Ciencias Exactas y Naturales, Universidad de Buenos Aires, Buenos Aires.

TCHILINGUIRIAN, P. y D. OLIVERA. 2012. Agricultura, ambiente y sustentabilidad agrícola en el desierto: el caso Antofagasta de la Sierra (Puna argentina, $26^{\circ} \mathrm{S}$ ). En Agricultura y Desierto, A. Korstanje y M. Quesada (Eds.), pp. 104-129. Ediciones Magna, San Miguel de Tucumán.

URQUIZA, S. 2009. Arqueofaunas del Alero Punta de la Peña 4: Implicaciones para el Manejo del Recurso Camelidae en Antofagasta de la Sierra, Puna Austral, Catamarca. Tesis Doctoral inédita. Universidad Nacional de Tucumán, San Miguel de Tucumán. 
URQUIZA, S. y C. ASCHERO. 2006. Avances en el estudio del recurso Camelidae: sitio Punta de la Peña 4, Antofagasta de la Sierra, provincia de Catamarca. En Actas del IV Congreso Mundial sobre Camélidos, D. E. Olivera, M. Miragaya y S. Puig (Eds.), pp. 364-368. Formato CD, Santa María de Catamarca.

URQUIZA, S. V., A. S. ROMANO y S. M. L. LÓPEZ CAMPENY. 2013. Historia ocupacional y prácticas sociales: Un análisis arqueofaunístico contextual. Sitio Piedra Horadada 2, Antofagasta de la Sierra, Catamarca, Argentina. En De la Puna a las Sierras: Avances y Perspectivas en Zooarqueología Andina, A. Izeta y G. Mengoni Goñalons (Eds.), pp. 121-144. British Archaeological Reports, Oxford.

VON DEN DRIESCH, A. 1976. A Guide to the Measurement of Animal Bones from Archaeological Sites. Peabody Museum of Archaeology and Ethology. Bulletin I, Universidad de Harvard: 137.
WHEELER, J. C. 1999. Patrones prehistóricos de utilización de los camélidos sudamericanos. Boletín de Arqueología PUCP 3: 297305 .

WING, E. 1972. Utilization of animal resources in the Peruvian Andes. En Andes 4: Excavations at Kotosh, Perú 1963 and 1964, I. Seiichi y K. Terada (Eds.), pp. 327-351. Tokyo University, Tokio.

YACOBACCIO, H. D y M. CATÁ. 2006. El uso de camélidos en la Quebrada de Humahuaca (110oDC). En Actas del IV Congreso Mundial de Camélidos, D. E. Olivera, M. Miragaya y S. Puig (Eds.), pp. 354-364. Santa María de Catamarca.

YACOBACCIO, H. D., C. M. MADERO, M. P. MALMIERCA y M. C. REIGADAS. 1997-1998. Caza, domesticación y pastoreo de camélidos en la Puna Argentina. Relaciones de la Sociedad Argentina de Antropología XXIIXXIII: 389-418. 